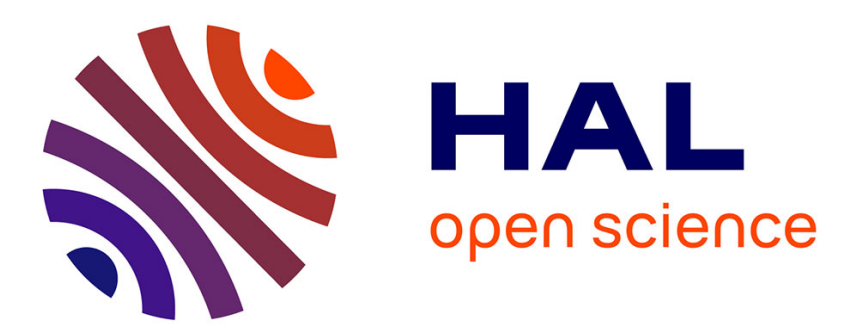

\title{
Evaluation of heat transfer coefficient of tungsten filaments at low pressures and high temperatures N.G. Chondrakis, F.V. Topalis
}

\section{To cite this version:}

N.G. Chondrakis, F.V. Topalis. Evaluation of heat transfer coefficient of tungsten filaments at low pressures and high temperatures. Applied Thermal Engineering, 2010, 31 (2-3), pp.258. 10.1016/j.applthermaleng.2010.09.005 . hal-00692334

\section{HAL Id: hal-00692334 \\ https://hal.science/hal-00692334}

Submitted on 30 Apr 2012

HAL is a multi-disciplinary open access archive for the deposit and dissemination of scientific research documents, whether they are published or not. The documents may come from teaching and research institutions in France or abroad, or from public or private research centers.
L'archive ouverte pluridisciplinaire HAL, est destinée au dépôt et à la diffusion de documents scientifiques de niveau recherche, publiés ou non, émanant des établissements d'enseignement et de recherche français ou étrangers, des laboratoires publics ou privés. 


\section{Accepted Manuscript}

Title: Evaluation of heat transfer coefficient of tungsten filaments at low pressures and high temperatures

Authors: N.G. Chondrakis, F.V. Topalis

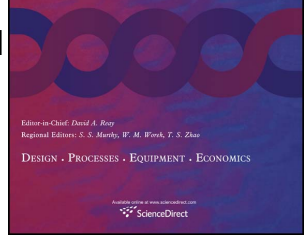

PII:

S1359-4311(10)00392-3

DOI:

10.1016/j.applthermaleng.2010.09.005

Reference: ATE 3232

To appear in: Applied Thermal Engineering

Received Date: 7 May 2010

Revised Date: 24 August 2010

Accepted Date: 4 September 2010

Please cite this article as: N.G. Chondrakis, F.V. Topalis. Evaluation of heat transfer coefficient of tungsten filaments at low pressures and high temperatures, Applied Thermal Engineering (2010), doi: 10.1016/j.applthermaleng.2010.09.005

This is a PDF file of an unedited manuscript that has been accepted for publication. As a service to our customers we are providing this early version of the manuscript. The manuscript will undergo copyediting, typesetting, and review of the resulting proof before it is published in its final form. Please note that during the production process errors may be discovered which could affect the content, and all legal disclaimers that apply to the journal pertain. 


\title{
Evaluation of heat transfer coefficient of tungsten
}

\section{filaments at low pressures and high temperatures}

\author{
N.G. Chondrakis ${ }^{1}$, F.V. Topalis \\ National Technical University of Athens, Department of Electrical and Computer Engineering, 9, Iroon \\ Politechniou St., Zografou, 15780 Athens, Greece
}

\section{Abstract}

The paper presents an experimental method for the evaluation of the heat transfer coefficient of tungsten filaments at low pressures and high temperatures. For this purpose an electrode of a T5 fluorescent lamp was tested under low pressures with simultaneous heating in order to simulate the starting conditions in the lamp. It was placed in a sealed vessel in which the pressure was varied from $1 \mathrm{kM}$ (kilo micron) to $760 \mathrm{kM}$. The voltage applied to the electrode was in the order of the filament's voltage of the lamp at the normal operation with the ballast during the preheating process. The operating frequency ranged from $\mathrm{DC}$ to $50 \mathrm{kHz}$. The experiment targeted on estimating the temperature of the electrode at the end of the first and the ninth second after initiating the heating process. Next, the heat transfer coefficient was calculated at the specific experimental conditions. A mathematical model based on the results was developed that estimates the heat transfer coefficient. The experiments under different pressures confirm that the filament's temperature strongly depends on the pressure.

\footnotetext{
${ }^{1}$ Corresponding author
} 
Keywords: heat transfer coefficient, fluorescent lamps, electronic ballast, low gas pressure, preheat ratio, nitrogen.

\section{Introduction}

Recently, a better understanding of the heat transfer from wires and fibers into gases or plasma (and vice versa) has been recognized as an important field of investigation [1]. Almost all the experimental researches deal with gas flow in a tube of small diameter with an outer cooling system. In the tube there is a metallic filament or fiber which undergoes a thermal change and its cooling or heating rate is measured. It is well known that experiments in an exactly static atmosphere suffer errors and inaccuracies of the recording instruments and their readings, because the temperature difference between the wire and its surroundings causes a relative gas flow over the hot wire.

In the present work a study was carried out for evaluating heat transfer in natural convection processes at wires used in light bulbs under low pressure. Fluorescent lamps use electric discharge to produce light. A moderate high-frequency voltage of a few Volts is applied to the electrodes at both ends of a straight or curved tube. The tube is under low pressure of approximately $1 \mathrm{mBar}$. The discharge is usually attained after a small period of preheating the electrodes. This time ranges from 0.5 to $2 \mathrm{~s}$. Preheating the electrodes to a temperature of $1000 \mathrm{~K}$ or higher, prior to ignition, initiates the discharge and protects the electrodes from losing their emitter mixture [2, 3, 4]. During the preheating period, the electrodes are heated and the acquired temperature depends on the heat transfer from the filaments to the gas mixture into the bulb. The whole phenomenon is dominated by the natural convection flow conditions. 
It is well documented that, depending on the applied voltage, the ambient temperature and the electric resistance of the electrode, the achieved electrode temperature remains constant. Furthermore, it is known that for stable gas temperature and provided that the mean free path of gas molecules or atoms is much larger than their diameter, electrode's thermal conductivity and heat transfer coefficient are independent of the gas pressure. Fluorescent tubes contain a mixture of inert gasses such as neon and argon in addition to a few milligrams of mercury. The atomic diameter (Van der Waals radius is about 1.4 to $1.55 \mathrm{~nm}$ ) of these gasses is much smaller than their mean free path $\left(10^{5} \mathrm{~nm}\right)$ at the low pressure of the tube. In such conditions, the variation in the tube pressure results in electrode temperature diversities during their preheating. This leads to the reduction of lamp life if the pressure is higher or lower than the manufacturer's recommended value. In this study is presented an experiment which shows the dependence of the electrode current on the pressure of gases in the tube. This is due to the change of the electrical resistance of the electrode under different pressures. The change in the electrical resistance is attributed to the change of the overall heat transfer coefficient on account of the change of the pressure. An informative diagram, related with filaments at different low pressures, is presented in [5] showing the dependence of electrode temperature (brightness temperature) on the argon pressure in the tube, when low current flows through the electrode.

Lamp electrodes are heated during preheating process applying AC voltage or current of constant amplitude, depending on the selected scenario from the manufacturer. In this study the constant voltage procedure was implemented. During this procedure, there is a short time delay for the current to stabilize, because its 
magnitude depends on the electrode temperature. Eventually, the current stabilizes when equilibrium is achieved between the electrode power supply and the heat transfer from the electrode to the gas atmosphere surrounding it. At low pressures a few days are required for accurate equilibrium [4, 6, 7], but for the precision of this study it is accepted that the stabilization of the current occurs in a few seconds.

During preheating if the heat transfer coefficient is high enough the electrode temperature falls. This results in lower electrical resistance of the electrode which permits more current flow.

Taking into account the above considerations, for a given applied voltage to the electrode, by measuring one of the parameters, such as the electrode current, the electrode resistance or its temperature, the other two can be evaluated. It is important for the lamp life that the electrode heating process reaches a temperature of at least $1000 \mathrm{~K}$. The temperature of the lamp cannot be measured directly, because of the fluoresced material already in the inner surface of the tube. Instead, the voltage and current can be measured at the end of the preheating procedure and from Ohm's law the corresponding (hot) resistance is evaluated. Since the value of the cold resistance of the electrode is known, the hot to cold resistance ratio (preheat ratio) is calculated. Preheat ratio is then used to compute the electrode temperature from a known formula or from available Tables where the electrode material is tabulated.

In this study the preheating conditions in a fluorescent lamp were simulated using real lamp electrodes. Fluorescent lamps' electrodes are made of tungsten wire covered with a mixture of barium, calcium and strontium carbonates. These carbonates, which are decomposed to oxides during lamp operation, do not contact the electric current but 
they facilitate the discharge process. The electrodes were placed in a chamber in which various pressures were applied under $D C$ and $A C$ voltage and their temperature was calculated. The results show that the value of the pressure significantly influences the electrode temperature. It is believed that these results will provide a better understanding of both the fluorescent lamp preheating process and gas properties of heat transfer.

\section{Experimental method}

\subsection{Test device}

A schematic of the experimental apparatuses is shown in Fig. 1. Three lamp electrodes were placed in a sealed vessel. The filaments were removed from the interior of broken T5 fluorescent linear lamps. This type of fluorescent lamp is recently replacing T8 or T12 types; hence it is of great interest to know their characteristics [8]. The breaking of the tubes was made smoothly by applying an incremental voltage to a wire of Nickel-Chromium alloy coiled around the tube. The filaments were placed in the vessel protruded, in order to exchange heat with their environment freely. Two of them were almost identical. They were taken from T5 - 14 Watt lamps. The third one was from a T5-24 Watt lamp. The electrodes were initially heated for several minutes in nitrogen atmosphere at about $500^{\circ} \mathrm{C}$ in order to reduce the strains in them. One of the three electrodes was used for the measurements. The other two were tested many times on secondary measurements in order to verify the results and check the conclusions for any potential errors.

The apparatus which was used to put the electrodes in was able to inhibit the suction of the air when it was under low pressure. It was a semi-hermetic reciprocating 
refrigeration compressor emptied from its electrical components. The three end caps with the lamp pin contacts were mounted on the lampholders which, in turn were connected with the six terminals of the 3-phase compressor. Its internal diameter was $162 \mathrm{~mm}$ and its external diameter was $200 \mathrm{~mm}$. The internal length of the chamber was $175 \mathrm{~mm}$, plus its mechanical department. Fig. 2 presents the inner part of the compressor with one electrode at the test position. This wiring made from the compressor's manufacturer, ensured the tightness of the chamber with regard to the connection of the inner part of it with the outer one. After the electrodes had been fixed, the chamber was evacuated to a pressure of $1 \mathrm{kM}$ (equals 1 Torr) and remained for one day without increasing it, thus ensuring the mechanical seal leakage. Then the vessel was filled with nitrogen up to atmospheric pressure and was evacuated again. Thus, the clearness of nitrogen was guarantied. In the course of the experiment, when the system was to be stored the apparatus was filled with nitrogen up to a pressure of $760 \mathrm{kM}$ to $800 \mathrm{kM}$ inhibiting the inflow of air.

In this study the electrodes' current was measured under atmospheric or sub atmospheric pressures while a DC or constant $A C$ voltage was applied. A vacuum pump was used to rarefy the nitrogen atmosphere in the vessel. Nitrogen or other inert gas is used in high temperature experiments to protect the filaments from fracture. The TIF 9450D vacuum gauge was used for measuring the pressure which was controlled with a vacuum pump. This gauge measures pressure in microns (M) or kilo microns (kM). The ambient temperature inside the laboratory during the experiment was within $23 \pm 3{ }^{\circ} \mathrm{C}$.

\subsection{Calculation of the temperature of the hot resistance}


The voltage was applied to the electrode through the terminals coming out of the chamber. The same leads were connected to the oscilloscope through a differential probe and a current probe. The oscilloscope recorded the exact electrode voltage and current at the ends of the filaments. Captures were recorded with the oscilloscope for a predetermined period of time. Using the abilities of the oscilloscope, at any desired moment of the heating process voltage and current were measured. Afterwards the Ohm's law was used in order to estimate the electrical resistance of the electrode. The corresponding electrode temperature was calculated from the equation:

$$
T_{h}=T_{c} \cdot\left(R_{h} / R_{c}\right)^{0.814}
$$

where $T_{c}$ is the ambient (i.e. chamber) temperature (usually $300 \mathrm{~K}$ ) and $R_{c}$ is the cold filament resistance. Correspondingly, $T_{h}$ and $R_{h}$ are the temperature and the resistance of the hot filament. It is considered that the filament has attained the ambient temperature $T_{c}$ before the heating process is started. Formula (1) is generally adopted to measure the hot filament temperature in fluorescent lamps [9]. At the end of the preheating period of a fluorescent lamp, which is the moment just prior to ignition, the ratio $R_{h} / R_{c}$ is called preheat ratio (or hot-to-cold resistance ratio). In fluorescent lamps a favorable value for $R_{h} / R_{c}$ is 4.25 or higher. When the preheat ratio is 4.25 the temperature of the electrode is $1000 \mathrm{~K}$, a fact that causes very low electrode erosion.

Verification for the estimated electrode temperature was performed by using tables for the resistivity $(\rho)$ of tungsten as a function of temperature. This was carried out with the following consideration. At first, the electrode's shape factor was evaluated. The resistivity of tungsten at $300 \mathrm{~K}$ is $5.65 \mu \Omega \cdot \mathrm{cm}$. The resistance at $300 \mathrm{~K}$ is measured and the shape factor $(I / S)$ of the filament is obtained, which is considered invariable. When a 
new resistance is known at an elevated unknown temperature, the new resistivity is calculated from the formula:

$$
R=\rho \cdot(I / S)
$$

Then the temperature is obtained from the table which gives the resistivity dependence of the temperature.

An alternative equation [10] for calculating the temperature for tungsten electrodes is:

$$
T=109.7+37.49 \cdot \rho-0.06552 \cdot \rho^{2}
$$

Equations (1) and (3) give accurate results in the region of our interest i.e. from $1000 \mathrm{~K}$ to $1300 \mathrm{~K}$.

\subsection{Instruments and measurements}

Each tungsten wire was heated independently and the oscilloscope captured both voltage and current changes. A Tektronix DPO4034 oscilloscope was used with current probe Tektronix TCP202 and High Voltage Differential probe Tektronix P 5200. A voltage regulator supplied DC or AC voltage for a fixed period of time. The voltage values were selected in order that the preheat ratio of the electrode does not exceed 4.5, which corresponds to a temperature of about $1020 \mathrm{~K}$. Higher temperatures have been avoided because they could damage the filaments.

The filament heating voltage was set successively to about $2 \mathrm{~V}, 4 \mathrm{~V}, 6 \mathrm{~V}$ and $8 \mathrm{~V}$ either when DC or AC voltage was applied. Keeping constant these values of the voltage was difficult because the predetermined voltage changed at the moment of the 
electrical connection with the electrode, especially at high frequency operation. The oscilloscope was monitored to capture the filament voltage and current for a $10 \mathrm{~s}$ period after the voltage application. From each capture the preheat ratio and the corresponding temperature was estimated at the first and the ninth second of the heating. The first second was considered in order to simulate the preheating period of a fluorescent lamp and the ninth second in order to have the temperature when the phenomenon stabilizes. It is significant to know the temperature of a lamp electrode at the moment of ignition which occurs within $2 \mathrm{~s}$ after applying the preheating voltage. An ongoing experiment in our laboratory utilizes rapid start and programmed start ballasts with a preheating period of 490,830 and 1470 ms respectively.

Both $D C$ and $A C$ voltage measurements were curried out. The frequencies used were $50 \mathrm{~Hz}, 10 \mathrm{kHz}$ and $50 \mathrm{kHz}$. The European frequency for the electromagnetic ballasts in fluorescent lamps is $50 \mathrm{~Hz}$ while $50 \mathrm{kHz}$ is more or less the applied frequency during preheating lamps with electronic ballasts and the upper limit for steady state operation. Usually the frequency during the whole preheating period in fluorescent systems is not constant. The switching frequency decreases and the lamp voltage increases correspondingly. When the lamp voltage reaches the lamp ignition level the discharge is attained and the frequency drops to the operating value, which is usually 45 to $50 \mathrm{kHz}$. The DC voltage was applied with a Heinzinger TN $30-600$ voltage regulator. A Thurlby Thandar Instruments TGA 1241 programmable arbitrary waveform generator was utilized for providing a sinusoidal voltage. The voltage was amplified by a proprietary device which was connected with the terminals of the electrodes.

\subsection{Basic assumptions}


The high frequency voltage usually causes an intense skin effect. The electrodes used in this study do not suffer from skin effect because their filament is too thin. In tungsten the skin depth at the frequency of $50 \mathrm{kHz}$ at $1000 \mathrm{~K}$ is about $0.2 \mathrm{~mm}$. The electrodes are of the type of triple coil and the diameter of the primary current-carrying wire is $0.07 \mathrm{~mm}$. Due to the small diameter of the coil it is concluded that the skin effect is insignificant, an assertion which is confirmed by the results. The diameter of the second coiled coil was measured with a micrometer at $0.45 \mathrm{~mm}$. The heat transfer is carried out by this coil because it is filled with the carbonates [11].

The increase in $\mathrm{AC}$ resistance is accurate only for an isolated and straight wire. For filaments like lamp electrodes, the resistance is affected by the proximity effect, which may cause changes in the $\mathrm{AC}$ resistance. The high temperature which increases in the coil during its heating complicates the skin effect since the value of the resistivity is temperature dependent [12]. The higher the resistivity the larger is the skin depth while resistivity increases with the conductor's temperature.

The self-inductance of the filament also complicates the theoretical inquiry of the subject because it depends on the permeability of the tungsten which affects skin depth. Nevertheless, the self-inductance of the filaments was measured at room temperature and was found to be insignificant. According to these considerations in the presentation of this study the skin effect and self-inductance do not play role.

\section{Results}

\subsection{Heating filaments}


Fluorescent lamp systems should not permit the heating of the electrodes for an extended time for the purpose of achieving higher temperature under lower voltage. Nor should high preheating voltage be supplied in order to reduce the preheating time. In both cases, during the preheating period glow current (discharge current between the electrodes) emerges which causes erosion to the electrodes. Consequently, the investigation of the preheating process is important.

Three different tungsten electrodes were removed from the fluorescent lamps and were used for the subsequent measurements. They had given the names: $1 / 14 \mathrm{~W}$, $2 / 14 \mathrm{~W}$ and $1 / 24 \mathrm{~W}$ and their resistances at $25^{\circ} \mathrm{C}$ were $9.72 \Omega, 9.10 \Omega$ and $2.51 \Omega$ respectively. Each measurement was carried out for a period of $10 \mathrm{~s}$ for every selected voltage at a fixed pressure. The vacuum pump sucked the nitrogen from the vessel to the desirable value of pressure. The DC voltage regulator or AC amplifier applied the predetermined voltage at one electrode. The voltage and current were measured from the obtained oscillogram one second and $9 \mathrm{~s}$ after the application of the voltage. The resistance of the hot wire was calculated using Ohm's law and next the corresponding preheat ratio was estimated too.

Fig. 3 shows a representative oscillogram of one capture. The line in the middle shows the electrode current variation. It takes a few seconds to stabilize the current. Stabilization is achieved after about $5 \mathrm{~s}$. The lower line represents the constant DC voltage while the upper line shows the hot resistance in real time after the oscilloscope's necessary mathematical elaboration. This line also depicts the rate of growth of the electrode temperature which is almost inversely proportional to the current. 
Fig. 4 shows the oscilloscope's capture of the previous situation when the frequency was $50 \mathrm{kHz}$. It is worth paying attention to the value of the voltage at the beginning of the process. During the first two or three seconds it is lower than the final value and then it gradually increases. This is due to the high frequency. This phenomenon was observed in frequencies of $10 \mathrm{kHz}$ and $50 \mathrm{kHz}$, and it is in agreement with the well known voltage reduction at high frequencies. For that matter the voltage at the tenth second was lower than the voltage set before the connection to the electrode's circuit.

The data of the oscillogram at $6 \mathrm{~V} \mathrm{DC}$ in connection with equation (1) were used to compute the filament temperature several times during the electrode heating which lasted $10 \mathrm{~s}$. The temperature versus time is shown in Fig. 5. In order to obtain this figure the sample $2 / 14 \mathrm{~W}$ was used and the pressure was $3.5 \mathrm{kM}$. The rhombic marks represent the experimental temperature estimation and the curve fitted line represents the best logarithmic one. The correlation coefficient squared of the curve is 0.9816 , which shows a good approximation, and for which the following logarithmic equation has been selected as the most appropriate and simple in order to best fit the measured data:

$$
T=100.46 \cdot \ln (t)+855.41
$$

Equation (4) is definitely valid only for the particular values of voltage and pressure.

Fig. 5 shows a rapid increase in temperature during the first second of the heating. This is the reason why lamp ballasts preheat the lamp filaments for approximately one second. 


\subsection{Measurements}

According to the described methodology Tables 1 and $\mathbf{2}$ present the measured values of the electrode voltage and current for the sample $1 / 14 \mathrm{~W}$. The temperature which was calculated using equation (1) is also shown. Equation (3) gives almost the same results. For comparison reasons, Table 3 shows the values of temperature according to equations (1) and (3) at DC voltage. The difference is less than $2 \%$. To calculate the temperature from (3) the thoughts of the paragraph 2.2 were used. The shape factor of $1 / 14 \mathrm{~W}$ sample is $10^{6} 1.72 \mathrm{~cm}^{-1}$ (for $300 \mathrm{~K}$ and cold resistance $9.72 \Omega$ ). From equation (2) the resistivity of the hot electrode is calculated and from (3) the corresponding temperatures. Table 1 shows the values for the first second of heating at the various pressures and frequencies while table 2 shows the measurements at the ninth second of heating. The values of these tables were used for the following elaboration.

Fig. 6 shows the electrode's temperature versus voltage under the same conditions of pressure and frequency but at a different moment of measurement. The upper trace corresponds to the recording of the temperature $9 \mathrm{~s}$ after starting the heating while the lower trace represents the temperature at the first second. It is observed that at the first second the temperature is about $100 \mathrm{~K}$ lower than that when stabilization has been achieved.

\section{Discussion}

\subsection{The influence of gas pressure on the filament's temperature}


Figs 7 and 8 show the dependence of the current on the filament voltage and vessel pressure at the end of the first and the ninth preheating second respectively. A series of measurements were carried out at five different pressures: $1.7 \mathrm{kM}, 3.5 \mathrm{kM}, 8.5$ $\mathrm{kM}, 71.4 \mathrm{kM}$ and one atmosphere $(760 \mathrm{kM})$, in order to construct these diagrams. The applied voltage had a step of about two volts (depending on the frequency) so that we had four or five measurements for each value of pressure. The value of the current in the figures was measured from the oscillogram one and nine seconds after the voltage application. The filament temperature should not exceed $1000 \mathrm{~K}$ by far, in order to protect the electrode from erosion. This is the reason why the applied voltage was less than $8 \mathrm{~V}$. The calculated temperature at this voltage was always approximately $1000 \mathrm{~K}$.

It is obvious from the lines that for constant voltage, the lower the pressure the lower is the current. This is explained by the fact that as the pressure gets higher the number of nitrogen molecules in the chamber increases. This results in a better heat transfer from the tungsten wire to the surrounding atmosphere, as more particles collide with the electrode.

Usually, in the literature, this result is not clarified and often the heat transfer coefficient is regarded as independent of the gas pressure under specific circumstances, such as for ideal gas or when the mean free path of the gas molecules is comparable to the main dimension of the specimen [13-15]. The unchangeable heat transfer is justified by the increase of the velocity and the mean free path of the atoms when the pressure is reduced [14]. However in the general case that is examined in this experiment the gas pressure influences the thermal conductivity and heat transfer [1316]. The thermal conductivity of a real gas, with increased deviation from ideal gas 
behaviour, is dependent on the pressure [14]. During this experiment, apart from nitrogen, helium and air atmospheres were also used in short extent, allowing us to obtain results which prove the increase of heat transfer with gas pressure.

Figs 9 and 10 show the change of preheat ratio for different values of gas pressure when the electrode was supplied with DC voltage. These curves show the corresponding electrode temperature change which was achieved by applying the appropriate voltage to the electrode. The measurements were carried out by reducing the pressure to the desired magnitude. The oscilloscope recorded the voltage and the change in the current. The hot resistance $R_{h}$ was computed simply by dividing the voltage with the current. The traces resulted from the $10 \mathrm{~s}$ captures of the oscilloscope and the estimation of hot to cold resistance ratio on the appropriate moment. Provided that the voltage is constant, it becomes clear that the lower the pressure the higher the preheat ratio, hence the higher the temperature of the electrode is.

Fig. 11 is another interesting diagram that shows the variation of hot resistance with pressure. The lines are for selected representative values of voltage, when the frequency is set at $50 \mathrm{kHz}$ at the end of the first heating second. It is clear that preheat ratio increases as the pressure decreases, especially at higher voltages.

Equation (1) is used to estimate the temperature, at a specific moment of the electrode heating, when the voltage and current are known. The curves in Figs 12a, $12 b, 12 c$ and $12 d$ show the temperature versus voltage nine seconds after heating the electrode. Each group of curves stands for DC or for AC voltage as shown on the diagrams. The points represent the measured values of voltage and current. The clear conclusion drawn from the diagrams is the indisputable dependence of the electrode's 
temperature on the pressure. Denser atmospheres remove more heat from the filament resulting in lower temperature. Each measurement was followed by an interval of at least 15 minutes before the next measurement. This period of time is not enough for complete cooling of the electrode but, according to other researchers [17] and investigations in our laboratory, within this segment of time the resistance of the filament is sufficiently restored.

The computation of the best-fit curves for the data of the diagrams of the figures 6 -10 and 12, results to lines with correlation coefficient squared $\left(R^{2}\right)$ greater than 0.99 while in figure 11 it varies in the range of $0.62-0.90$.

\subsection{The influence of gas pressure on the heat transfer}

During thermal equilibrium, nitrogen molecules collide with the tungsten wire and they exchange energy. The transfer of energy between the gas and the filament is determined by the magnitude of the heat transfer coefficient $\left(h_{0}\right)$. The coefficient of heat transfer here is a combination of convection and conduction from the wire to the gas. If molecules of the gas with a mean energy corresponding to the ambient temperature $T_{c}$ are incident on the solid surface of electrode at temperature $T_{h}$ the gas atoms will have a mean energy corresponding to a temperature with values between $T_{h}$ and $T_{c}$. In this experiment it is assumed that the gas molecules reacquire the ambient temperature almost immediately because the vessel is big in comparison with the electrode. The vessel is metallic and it is a very good thermal conductor with its environment, so it is acceptable that its interior is of constant temperature along the $10 \mathrm{~s}$ period of the electrode's heating. 
The tungsten electrode is also losing thermal energy in other ways. At first, energy is lost through the lead support connections. Energy is also lost due to thermionic emission of electrons depending on the wire's temperature. At the temperatures of this experiment, these losses are insignificant and they can be ignored. The hot wire loses energy due to radiation too.

The total heat lost per unit time radiated from the hot wire at thermal equilibrium is expressed by the following equation:

$$
N=h_{0} \cdot A \cdot\left(T_{h}-T_{c}\right)+\varepsilon \cdot \alpha \cdot A \cdot\left(T_{h}^{4}-T_{c}^{4}\right)
$$

where $N$ (in Watts) is the electric power of the wire, $A$ (in $\mathrm{m}^{2}$ ) is the surface area, $\varepsilon$ is the average emissivity of the hot wire and $\alpha\left(\right.$ in $\left.\mathrm{J} \mathrm{s}^{-1} \mathrm{~m}^{-2} \mathrm{~K}^{-4}\right)$ is the Stefan - Boltzmann constant. Emissivity $\varepsilon$ is a correction function that takes into account that ideal black bodies (for which $\varepsilon=1$ ) do not exist in reality. The $\varepsilon$ depends on the wavelength of radiation and the wire temperature. The coefficient $h_{o}$ depends also on temperature and other factors connected with the apparatus used and the prevailing conditions.

Regarding all this difficulty an overall heat transfer coefficient $(h)$ is usually employed that is estimated experimentally for specific cases [10]. The coefficient $h$ incorporates gaseous heat transfer besides radiation losses. The following equation expresses these assumptions:

$$
N=h \cdot A \cdot\left(T_{h}-T_{c}\right)
$$

The power $N$ is computed from the equation $N=V \cdot I$ (rms values). We obtain the electrode voltage and current values experimentally so that $N$ is easily estimated. The outer surface area might be found if the diameter $D$ and the length $L$ of the wire were 
known. The filament is considered to be cylindrical of a total length $L$. The diameter was $0.45 \mathrm{~mm}$ and the length was measured $28 \mathrm{~mm}$. The outer surface area $A$ was estimated as follows and it is the effective thermal surface:

$$
A=L \cdot \pi \cdot D
$$

The length $L$ is considered constant as the change of the coefficient of thermal expansion of tungsten at the range of the temperatures of the experiment is insignificant [18].

Equation (7) gives the surface area which after replacement in (6) gives the heat transfer coefficient by:

$$
h=V \cdot I / L \cdot \pi \cdot D \cdot\left(T_{h}-T_{c}\right)
$$

The filament current $I$ and the corresponding voltage $V$ are measured while the temperature $T_{h}$ is estimated appropriately. Usually $h$ is multiplied by the temperature difference and the heat transfer is estimated in units of $\mathrm{W} \mathrm{m}^{-2}[16]$.

The previous analysis was based on the properties of the continuum molecule regime since the Knudsen numbers for nitrogen in the experimental conditions were much smaller than 1 . Specifically, they ranged from $10^{-4}$ at the atmospheric pressure at low temperature $(300 \mathrm{~K})$ to $3 \cdot 10^{-7}$ at pressure $1 \mathrm{kM}$ at $1000 \mathrm{~K}[16]$. The mean free path for nitrogen was estimated taking into account that its molecular diameter is $300 \mathrm{pm}$. The representative physical length scale (e.g. filament) was accepted to be $1 \mathrm{~mm}$.

The points in Fig. 13 reflect the variation of the heat transfer coefficient versus temperature at various pressures at the frequency of $50 \mathrm{kHz}$, during thermal equilibrium (9 s heating). The values of this figure are valid for the fluorescent lamp electrodes of 
the shape and the resistance that they employed. In this diagram the $h$ is in the units of $\mathrm{W} \mathrm{m}^{-2} \mathrm{~K}^{-1}$.

The heat transfer coefficient is very low in low pressures because of the thin atmosphere around the filament. It had also low values because of the static atmosphere around the filament (natural convection). These conditions are compared to the situation in a fluorescent lamp. It was also found, as it was expected, that the heat transfer was higher at elevated pressures and temperatures too.

The construction of the diagram in Fig. 13 was based on the following ideas. The heat transfer coefficient $h$ is a function of $T$ and $P$ and although it is linearly dependent on the temperature its dependence on the pressure is highly non linear. The general form of $h$ is:

$$
h=a(P) \cdot T+b(P)
$$

The $a$ and $b$ are variables depending on the pressure (for the given frequency). For this formula $h$ is in $\mathrm{W} \mathrm{m}^{-2} \mathrm{~K}^{-1}, T$ in $\mathrm{K}$ and $P$ in $\mathrm{kM}$. The curve fitting analysis on both $a$ and $b$ that was performed, assuming that the most appropriate form for them is the power and exponential respectively, produced the following result:

$$
h=0.03 \cdot T \cdot P^{0.1}+7.9 \cdot e^{-0.001 \cdot P}
$$

The points for each pressure of Fig.13 show a very strong linear relationship and the corresponding squares of the correlation coefficients $\left(R^{2}\right)$ are shown in the Table 4 . However, the best fit regression lines are not drawn here. Instead, the lines are drawn on the basis of the equation (10) which represents a general formula that describes the heat transfer process. In this way, all lines follow one single formula. 
This formula signifies that $h$ is linearly dependent on the temperature at constant pressure. At pressures usually applied in the fluorescent lamps (lower than $10 \mathrm{kM}$ ) the part $7.9 \cdot e^{-0.001 P}$ in (10) almost equals 7.9 and $P^{0.1}$ varies from 1 to 1.25 , hence heat transfer coefficient can be roughly estimated by:

$$
h=0.03 T+7.9
$$

It is worth mentioning that equation (10) holds for the experimental conditions described (sample shape and material, pressure conditions, etc) and the units as were given above. Under different conditions different formulas would hold. The equation (11) holds only for the fluorescent lamps.

An important conclusion from (11) is that this equation gives $h$ when the pressure is very low. However, when there is a thin atmosphere around the electrode, the heat transfer from the filament to the gas by convection is infinitesimal. In addition, the heat transfer by conduction to the support connections is stabilized at a low rate shortly. As a consequence, equation (11) gives an approximation of the heat transfer coefficient by radiation in connection with the temperature of the electrode.

In order to perform a significance test between the data from the measurements and the heat transfer coefficient derived from the equation (10) the t-test was applied. The 0.05 level of significance was accepted. It is obvious that for the selected significance level the proposed equation (10) is statistically significant except for the atmospheric pressure. The correlation coefficients $(r)$ for the same variables are higher than 0.97 which indicates a strong relationship at the previous level of significance. The interpretation of the resulted values is that there is a strong correlation between $h$ and $T$ through (10). Table 4 presents the results from both tests. 
Another series of measurements were carried out at pressure $3.5 \mathrm{kM}$ but nitrogen was replaced with helium in the vessel. The frequency was set to $50 \mathrm{kHz}$. The heat transfer coefficient of the new gas was calculated and it is presented in Fig. 14 in parallel with nitrogen under the same conditions for comparative reasons. It is verified that the lighter the gas the higher the heat transfer. Moreover it is confirmed that the difference in heat transfer between the two gases is similar to that which was found in [10] where the tested gases were helium (with molecular weight $4 \mathrm{gr} / \mathrm{mol}$ ) and argon (with molecular weight $40 \mathrm{gr} / \mathrm{mol}$ ). In this experiment nitrogen has smaller molecular weight $(28 \mathrm{gr} / \mathrm{mol})$.

\section{Conclusions}

In this study a method is presented that shows the way to measure the heat transfer coefficient of an electrode of T5 fluorescent lamp in low nitrogen pressure. The electrode was placed in a vessel of low pressure (almost vacuum) and it was heated at various voltages and frequencies until its temperature reached $1000 \mathrm{~K}$. The electrode's current was recorded by oscilloscope for a heating period of $10 \mathrm{~s}$ and the growth of the filament's resistance was computed. The temperature of the same electrode was estimated at the first and the ninth second of the heating. A formula is proposed for evaluating its temperature increase in real time for the first ten seconds of the heating process. This time is considered as long enough for thermal equilibrium between the filament and the gas.

The goal of this study is to gain a better understanding of the behavior and operation of lamps' electrodes during their preheating period with rapid and programmed start ballasts in fluorescent lamps. It was shown that the filling pressure of 
the inert gas has an impact on the value of the electrode temperature just prior to the discharge accomplishment. The results show that the lower the pressure the higher the temperature of the electrode. This was explained by the increase of heat transfer from the electrode to its environment with the increase of the pressure.

Moreover this method and the results provide a prediction of the heat transfer coefficient in electrodes when they operate at very low or near atmospheric pressure in nitrogen. A formula is proposed to predict the heat transfer coefficient in connection with the electrode's temperature and the pressure.

This experiment can provide some guidance to lamp researchers for verifying the lamp pressure. Although the approach is not adequately precise and does not represent all the physical processes that occur in the lamp electrodes, however it is expected to be a guide to lamp designers. It will help in the electrode's modeling thus leading to more quantitative analysis of electrode phenomena and their improved design.

\section{Acknowledgements}

The authors acknowledge the important support of A. Bassias and I. Gonos to the scientific part of this paper. The technical contribution of I. Pashalidis and A. Mitropoulos $^{\dagger}$ to this project was great.

\section{References}

[1] N. Lj. Perović, K. D. Maglić G. S. Vuković, Thermophysical properties of tungsten electrodes by subsecond pulse calorimetry, International Journal of Termophysics. vol. 17, No 5 (1996) 1047-1055. 
[2] M. Haverlag, A. Kraus, J. Sorman, J. Heuvelmans, A. Geven, L. Kaldenhoven, G. Heijne, High-Frequency Cold Ignition of Fluorescent Lamps, Journal of Physics D: Applied Physics. 35 (2002) 1695-1701.

[3] F. T. Wakabayashi, M. A. G. de Brito, G. S. Ferreira, C. A. Canesin, Setting the preheating and steady-state operation of electronic ballasts, considering electrodes of hot-cathode fluorescent lamps, IEEE Transactions on Power Electronics. Vol. 22, No. 3 (2007) 899-911

[4] T. Yasuda, M. Kando, Improvement of the luminous run-up characteristics in ballast-integrated compact fluorescent lamps covered with outer globes, Leukos. Vol. 4, No. 1 (2007) 57-70.

[5] K. J. Misono "The cathode fall voltage of low current fluorescent lamps", Journal of Light and Visual Environment. Vol.16, No. 2 (1992) 53-60.

[6] R. L. Lalauze, J. H. Meunier, Kinetics interpretation of $\mathrm{NiO}$ electrical conductivity under low oxygen pressures, Oxidation of metals. Vol. 13, No. 4 (1979) 301-309.

[7] R. L. Lalauze, J. H. Meunier, Experimental study of NiO electrical conductivity changes under low oxygen pressures, Oxidation of metals. Vol. 12, No. 2 (1978) 183-190.

[8] A. S. dos Santos, M. Toss, F. S. dos Reis, R. Tonkoski, The influence of programmed ballast in T5 fluorescent lamp lifetime, IEEE Industrial Electronics Society, $31^{\text {st }}$ annual conference of IEEE. (2005).

[9] G. W. Mortimer, Real-Time Measurement of Dynamic Filament Resistance, Journal of the Illuminating Engineering Society. (1998) 22-28. 
[10] F. W. Giacobbe, Determination of gaseous heat transfer coefficients at elevated temperatures, Applied Thermal Engineering. 25 (2005) 205-225.

[11] T. F. Soules, J. H. Ingold, A. K. Bhattacharya, R. H. Springer, Thermal Model of the Fluorescent Lamp Electrode, Journal of the Illuminating Engineering Society. (1989) 81-92.

[12] B. C. Sales and M. B. Maple, Low-frequency electrical resistance of iron, cobalt and nickel in the vicinity of their Curie temperatures, Applied Physics A. 31 (1983) $115-117$

[13] C. V. Madhusudana, Thermal Contact conductance, Springer, 1996, pp. 53.

[14] G. Nellis, S. Klein, Heat Transfer, Cambridge University Press, 2009.

[15] Y. A. Cengel, A. J. Ghajar, Heat and mass transfer, McGraw-Hill, fourth edition, 2009, pp. 20, 399.

[16] Xi Chen, Heat transfer to a metallic wire exposed to a plasma flow for great Knudsen numbers, J. Phys. 30 (1997)1885-1892.

[17] Y. Ji, R. Davis, C. O'Rourke, E. W. M. Chui, Compatibility Testing of Fluorescent Lamp and Ballast Systems, IEEE Transactions on Industry Applications. Vol. 35, No. 6, (1999) 1271-1276.

[18] L. S. Dubrovinsky, S. K. Saxena, Thermal expansion of periclase (MgO) and tungsten (W) to melting temperatures, Phys. Chem. Minerals. 24 (1997) 547-550. 
Table 1 - Electrode voltage, current and temperature for the selected pressures at the first second of the heating.

\begin{tabular}{|c|c|c|c|c|c|c|c|c|c|c|c|c|}
\hline \multirow{2}{*}{$\frac{1^{\text {st }} \text { sec }}{\text { P }}$} & \multicolumn{3}{|c|}{ DC } & \multicolumn{3}{|c|}{$50 \mathrm{~Hz}$} & \multicolumn{3}{|c|}{$10 \mathrm{kHz}$} & \multicolumn{3}{|c|}{$50 \mathrm{kHz}$} \\
\hline & $\begin{array}{l}\mathrm{V} \\
(\mathrm{V})\end{array}$ & $\begin{array}{c}\text { I } \\
(\mathrm{mA})\end{array}$ & $\begin{array}{c}\mathrm{T} \\
(\mathrm{K})\end{array}$ & $\begin{array}{c}\mathrm{V} \\
(\mathrm{V})\end{array}$ & $\begin{array}{c}\text { I } \\
(\mathrm{mA})\end{array}$ & $\begin{array}{c}\mathrm{T} \\
(\mathrm{K})\end{array}$ & $\begin{array}{c}\mathrm{V} \\
(\mathrm{V})\end{array}$ & $\begin{array}{c}\mathrm{I} \\
(\mathrm{mA})\end{array}$ & $\begin{array}{c}\mathrm{T} \\
(\mathrm{K})\end{array}$ & $\begin{array}{c}\mathrm{V} \\
(\mathrm{V})\end{array}$ & $\stackrel{1}{\prime}$ & $\begin{array}{c}\mathrm{T} \\
(\mathrm{K})\end{array}$ \\
\hline 1.7 & 2.08 & 142 & 420 & 2.16 & 128 & 471 & 1.99 & 129 & 438 & 1.63 & 121 & 392 \\
\hline 1.7 & 4,00 & 172 & 611 & 4.29 & 158 & 693 & 3.68 & 161 & 603 & 3.51 & 160 & 583 \\
\hline 1.7 & 6.16 & 190 & 801 & 6.71 & 178 & 906 & 5.88 & 177 & 817 & 5.38 & 179 & 753 \\
\hline 1.7 & 8.08 & 202 & 951 & 8.34 & 188 & 1034 & 7.32 & 189 & 926 & 6.89 & 189 & 881 \\
\hline 3.5 & 2.02 & 143 & 407 & 2.25 & 136 & 463 & 2.41 & 144 & 468 & 1.35 & 110 & 363 \\
\hline 3.5 & 3.98 & 176 & 598 & 4.19 & 165 & 657 & 4.43 & 174 & 658 & 3.21 & 159 & 545 \\
\hline 3.5 & 6.12 & 196 & 777 & 6.22 & 180 & 844 & 6.09 & 186 & 808 & 5.04 & 182 & 705 \\
\hline 3.5 & 8.23 & 208 & 942 & 8.23 & 192 & 1006 & 6.92 & 193 & 870 & 7.36 & 199 & 892 \\
\hline 8.5 & 2.07 & 148 & 404 & 2.22 & 136 & 458 & 1.87 & 134 & 403 & 1.32 & 112 & 352 \\
\hline 8.5 & 4.02 & 184 & 581 & 4.28 & 171 & 649 & 3.52 & 170 & 556 & 3.06 & 163 & 514 \\
\hline 8.5 & 6.15 & 199 & 770 & 6.66 & 186 & 869 & 5.40 & 191 & 717 & 5.11 & 190 & 688 \\
\hline 8.5 & 8.09 & 211 & 918 & 8.26 & 195 & 996 & 7.62 & 203 & 903 & 7.01 & 201 & 850 \\
\hline 71.4 & 2.05 & 147 & 403 & 2.11 & 139 & 432 & 1.68 & 127 & 386 & 1.61 & 126 & 375 \\
\hline 71.4 & 4.03 & 184 & 582 & 4.11 & 172 & 625 & 3.27 & 169 & 526 & 3.15 & 168 & 513 \\
\hline 71.4 & 6.09 & 203 & 752 & 6.01 & 187 & 795 & 5.22 & 191 & 697 & 5.20 & 193 & 689 \\
\hline 71.4 & 8.19 & 217 & 907 & 7.95 & 201 & 942 & 7.26 & 203 & 868 & 7.00 & 205 & 836 \\
\hline 760 & 2,00 & 152 & 385 & 1.95 & 132 & 423 & 1.50 & 118 & 374 & 1.44 & 115 & 369 \\
\hline 760 & 4,00 & 193 & 557 & 3.90 & 170 & 605 & 2.99 & 166 & 496 & 2.85 & 164 & 482 \\
\hline 760 & 6.10 & 213 & 724 & 5.88 & 190 & 771 & 4.71 & 192 & 638 & 4.52 & 191 & 620 \\
\hline 760 & 8.05 & 223 & 874 & 7.86 & 207 & 911 & 6.50 & 207 & 781 & 6.13 & 204 & 753 \\
\hline 760 & & & & & & & 8.44 & 219 & 922 & 7.71 & 216 & 866 \\
\hline
\end{tabular}


Table 2 - Electrode voltage, current and temperature for the selected pressures at the ninth second of the heating.

\begin{tabular}{|c|c|c|c|c|c|c|c|c|c|c|c|c|}
\hline \multirow{2}{*}{$\begin{array}{c}9^{\text {th }} \mathrm{sec} \\
\mathrm{P} \\
(\mathrm{kM})\end{array}$} & \multicolumn{3}{|c|}{ DC } & \multicolumn{3}{|c|}{$50 \mathrm{~Hz}$} & \multicolumn{3}{|c|}{$10 \mathrm{kHz}$} & \multicolumn{3}{|c|}{$50 \mathrm{kHz}$} \\
\hline & $\begin{array}{l}\mathrm{V} \\
(\mathrm{V})\end{array}$ & $\begin{array}{c}\text { I } \\
(\mathrm{mA})\end{array}$ & $\begin{array}{c}\mathrm{T} \\
(\mathrm{K})\end{array}$ & $\begin{array}{l}\mathrm{V} \\
(\mathrm{V})\end{array}$ & $\begin{array}{c}\mathrm{I} \\
(\mathrm{mA})\end{array}$ & $\begin{array}{c}\mathrm{T} \\
(\mathrm{K})\end{array}$ & $\begin{array}{l}\mathrm{V} \\
(\mathrm{V})\end{array}$ & $\begin{array}{c}\text { I } \\
(\mathrm{mA})\end{array}$ & $\begin{array}{c}\mathrm{T} \\
(\mathrm{K})\end{array}$ & $\begin{array}{c}\mathrm{V} \\
(\mathrm{V})\end{array}$ & $\begin{array}{c}\mathrm{I} \\
(\mathrm{mA})\end{array}$ & $\begin{array}{c}\mathrm{T} \\
(\mathrm{K})\end{array}$ \\
\hline 1.7 & 2.08 & 114 & 502 & 2.17 & 101 & 573 & 2.12 & 104 & 549 & 1.74 & 98 & 491 \\
\hline 1.7 & 4.01 & 142 & 716 & 4.30 & 130 & 814 & 3.90 & 129 & 757 & 3.83 & 130 & 741 \\
\hline 1.7 & 6.16 & 164 & 903 & 6.71 & 154 & 1019 & 6.17 & 154 & 952 & 5.63 & 149 & 907 \\
\hline 1.7 & 8.08 & 180 & 1044 & 8.35 & 167 & 1140 & 7.54 & 166 & 1054 & 7.10 & 163 & 1019 \\
\hline 3.5 & 2.03 & 117 & 482 & 2.24 & 107 & 561 & 2.66 & 117 & 600 & 1.49 & 94 & 447 \\
\hline 3.5 & 3.98 & 148 & 688 & 4.17 & 134 & 775 & 4.67 & 144 & 801 & 3.48 & 131 & 681 \\
\hline 3.5 & 6.13 & 170 & 874 & 6.20 & 155 & 951 & 6.35 & 161 & 940 & 5.35 & 153 & 852 \\
\hline 3.5 & 8.23 & 188 & 1023 & 8.24 & 173 & 1096 & 7.18 & 169 & 998 & 7.55 & 172 & 1025 \\
\hline 8.5 & 2.07 & 121 & 476 & 2.20 & 109 & 545 & 2.03 & 109 & 534 & 1.44 & 96 & 428 \\
\hline 8.5 & 4.03 & 154 & 673 & 4.29 & 141 & 761 & 3.75 & 137 & 698 & 3.35 & 132 & 656 \\
\hline 8.5 & 6.16 & 176 & 853 & 6.66 & 166 & 953 & 5.58 & 160 & 850 & 5.30 & 157 & 828 \\
\hline 8.5 & 8.10 & 194 & 984 & 8.26 & 179 & 1068 & 7.87 & 180 & 1022 & 7.30 & 177 & 975 \\
\hline 71.4 & 2.05 & 123 & 466 & 2.10 & 113 & 509 & 1.84 & 109 & 471 & 1.67 & 104 & 452 \\
\hline 71.4 & 4.04 & 159 & 657 & 4.08 & 143 & 722 & 3.47 & 139 & 648 & 3.42 & 139 & 640 \\
\hline 71.4 & 6.10 & 181 & 827 & 6.03 & 167 & 875 & 5.42 & 164 & 814 & 5.45 & 165 & 813 \\
\hline 71.4 & 8.19 & 203 & 957 & 7.99 & 186 & 1007 & 7.42 & 183 & 961 & 7.19 & 183 & 937 \\
\hline 760 & 2.00 & 129 & 439 & 1.95 & 112 & 483 & 1.60 & 104 & 437 & 1.54 & 102 & 430 \\
\hline 760 & 4.00 & 168 & 623 & 3.93 & 150 & 674 & 3.17 & 143 & 588 & 3.07 & 141 & 579 \\
\hline 760 & 6.10 & 191 & 791 & 5.94 & 175 & 832 & 4.91 & 168 & 736 & 4.71 & 166 & 719 \\
\hline 760 & 8.05 & 209 & 922 & 7.88 & 194 & 962 & 6.71 & 188 & 866 & 6.31 & 185 & 835 \\
\hline 760 & & & & & & & 8.61 & 206 & 985 & 7.82 & 200 & 933 \\
\hline
\end{tabular}


Table 3 - Electrode temperature according to equations (1) and (3).

\begin{tabular}{ccccccc}
\hline $\begin{array}{c}\mathrm{V} \\
(\mathrm{V})\end{array}$ & $\begin{array}{c}\mathrm{I} \\
(\mathrm{mA})\end{array}$ & $\begin{array}{c}\mathrm{T}(\mathrm{K}) \\
\text { according } \\
(1)\end{array}$ & $\begin{array}{c}\mathrm{R}_{\mathrm{h}} \\
(\Omega)\end{array}$ & $\begin{array}{c}\rho \\
(\mu \Omega \cdot \mathrm{cm})\end{array}$ & $\begin{array}{c}\mathrm{T}(\mathrm{K}) \\
\text { according } \\
(3)\end{array}$ & $\begin{array}{c}\text { Difference } \\
(\%)\end{array}$ \\
\hline 2.08 & 142 & 420 & 14.65 & 8.51 & 424 & 1.10 \\
4.00 & 172 & 611 & 23.26 & 13.52 & 605 & -1.09 \\
6.16 & 190 & 801 & 32.42 & 18.84 & 793 & -1.00 \\
8.08 & 202 & 951 & 40.00 & 23.25 & 946 & -0.46 \\
2.02 & 143 & 407 & 14.13 & 8.21 & 413 & 1.42 \\
3.98 & 176 & 598 & 22.61 & 13.14 & 591 & -1.04 \\
6.12 & 196 & 777 & 31.22 & 18.15 & 769 & -1.07 \\
8.23 & 208 & 942 & 39.57 & 23.00 & 937 & -0.50 \\
2.07 & 148 & 404 & 13.99 & 8.13 & 410 & 1.51 \\
4.02 & 184 & 581 & 21.85 & 12.70 & 575 & -0.97 \\
6.15 & 199 & 770 & 30.90 & 17.96 & 762 & -1.08 \\
8.09 & 211 & 918 & 38.34 & 22.29 & 913 & -0.60 \\
2.05 & 147 & 403 & 13.95 & 8.10 & 409 & 1.54 \\
4.03 & 184 & 582 & 21.90 & 12.73 & 576 & -0.98 \\
6.09 & 203 & 752 & 30.00 & 17.44 & 744 & -1.12 \\
8.19 & 217 & 907 & 37.74 & 21.94 & 901 & -0.64 \\
2.00 & 152 & 385 & 13.16 & 7.64 & 393 & 2.12 \\
4.00 & 193 & 557 & 20.73 & 12.04 & 552 & -0.83 \\
6.10 & 213 & 724 & 28.64 & 16.65 & 716 & -1.16 \\
8.05 & 223 & 874 & 36.10 & 20.98 & 868 & -0.76 \\
& & & & & &
\end{tabular}


Table 4. Significance test for different pressures.

\begin{tabular}{cccc}
\hline $\mathrm{P}(\mathrm{kM})$ & $\mathrm{R}^{2}$ & $\mathrm{t}$-value & $\mathrm{r}$ \\
\hline 1.7 & 0,9772 & 0.0016 & 0.9885 \\
3.5 & 0,9914 & 0.0716 & 0.9959 \\
8.5 & 0,9523 & 0.0500 & 0.9759 \\
71.4 & 0,9896 & 0.0378 & 0.9948 \\
760 & 0,9991 & 0.7832 & 0.9996
\end{tabular}




\begin{tabular}{|c|c|c|c|}
\hline \multicolumn{2}{|c|}{ Nomenclature } & \multirow{2}{*}{$\begin{array}{l}R_{h} \\
R_{c}\end{array}$} & \multirow{2}{*}{$\begin{array}{l}\text { electrical resistance of the } \\
\text { hot electrode }[\Omega] \\
\text { electrical resistance of the } \\
\text { cold electrode }[\Omega]\end{array}$} \\
\hline$T$ & $\begin{array}{l}\text { temperature of the heated } \\
\text { electrode }[\mathrm{K}]\end{array}$ & & \\
\hline$T_{h}$ & $\begin{array}{l}\text { temperature of the hot } \\
\text { electrode }[\mathrm{K}]\end{array}$ & $h_{0}$ & $\begin{array}{l}\text { heat transfer coefficient between } \\
\text { gas and the electrode }\left[\mathrm{W} /\left(\mathrm{m}^{2} \mathrm{~K}\right)\right]\end{array}$ \\
\hline$T_{c}$ & $\begin{array}{l}\text { temperature of the cold } \\
\text { electrode }[\mathrm{K}]\end{array}$ & $h$ & $\begin{array}{l}\text { overall heat transfer coefficient } \\
{\left[\mathrm{W} /\left(\mathrm{m}^{2} \mathrm{~K}\right)\right]}\end{array}$ \\
\hline$P$ & pressure $[\mathrm{kM}=1$ Torr $]$ & $D$ & diameter of the electrode [m] \\
\hline$N$ & power of the filament $[\mathrm{W}]$ & 1 & length of the coiled filament [m] \\
\hline$\alpha$ & $\begin{array}{l}\text { Stefan-Boltzmann constant } \\
{\left[5.67 \cdot 10^{-8} \mathrm{~J} \mathrm{~K}^{-4} \mathrm{~m}^{-2} \mathrm{~s}^{-1}\right]}\end{array}$ & $A$ & $\begin{array}{l}\text { outer surface of the coiled filament } \\
{\left[\mathrm{m}^{2}\right]}\end{array}$ \\
\hline$\varepsilon$ & emissivity & $L$ & external length of the electrode [m] \\
\hline$\rho$ & resistivity $[\mu \Omega \mathrm{cm}]$ & $S$ & cross section of the filament $\left[\mathrm{m}^{2}\right]$ \\
\hline$R^{2}$ & correlation coefficient squared & $r$ & correlation coefficient \\
\hline
\end{tabular}




\section{Figure captions}

Figure 1. Experimental setup for low pressure heating study.

Figure 2. The interior of the vessel with one electrode.

Figure 3. Oscillogram for the sample $1 / 14 \mathrm{~W}$ for $10 \mathrm{~s}(1 \mathrm{~s} / \mathrm{div})$ at pressure $8.5 \mathrm{kM}, \mathrm{DC}$ voltage. Upper trace: hot resistance, middle trace: current (200 mA/div), lower trace: $6 \mathrm{~V}$ DC voltage (5 V/div).

Figure 4. Oscillogram for the sample 1/14W for $10 \mathrm{~s}(1 \mathrm{~s} / \mathrm{div})$ at pressure $8.5 \mathrm{kM}, 50$ kHz. Upper trace: voltage (10 V/div), lower trace: current (200 mA/div).

Figure 5. Tungsten filament heating curve (best fit of data points by logarithmic curve). Pressure $3.5 \mathrm{kM}$, voltage $6 \mathrm{~V}$ DC.

Figure 6. Electrode's temperature versus voltage at the end of the first and the ninth seconds of heating (frequency $50 \mathrm{kHz}$, pressure $1.7 \mathrm{kM}$ ).

Figure 7. Current variation with voltage and pressure in sample $1 / 14 \mathrm{~W}$ at the first heating second. Frequency: $50 \mathrm{kHz}$.

Figure 8. Current variation with voltage and pressure in sample $1 / 14 \mathrm{~W}$ at the ninth heating second. Frequency: $50 \mathrm{kHz}$.

Figure 9. Sample 1/14W. Preheat ratio versus DC voltage, $1 \mathrm{~s}$ after starting the heating at various pressures.

Figure 10. Sample 1/14W. Preheat ratio versus DC voltage, $9 \mathrm{~s}$ after the starting of the heating at various pressures.

Figure 11. Preheat ratio dependence on pressure for various voltages at the end of the first second of heating. Sample 1/14W, frequency $50 \mathrm{kHz}$. 
Figure 12a, b, c and d. Temperature dependence on voltage for the selected frequencies at different pressures (measurements taken $9 \mathrm{~s}$ after ignition).

Figure 13. Sample 1/14W: Variation of the overall heat transfer coefficient with the wire temperature at various gas pressures, at $50 \mathrm{kHz}$, 9s after ignition. Points: According to equation (8), Lines: Best fit using equation (10).

Figure 14. Heat transfer coefficient for nitrogen and helium at $3,5 \mathrm{kM}, 50 \mathrm{kHz}, 9 \mathrm{~s}$ after ignition. 


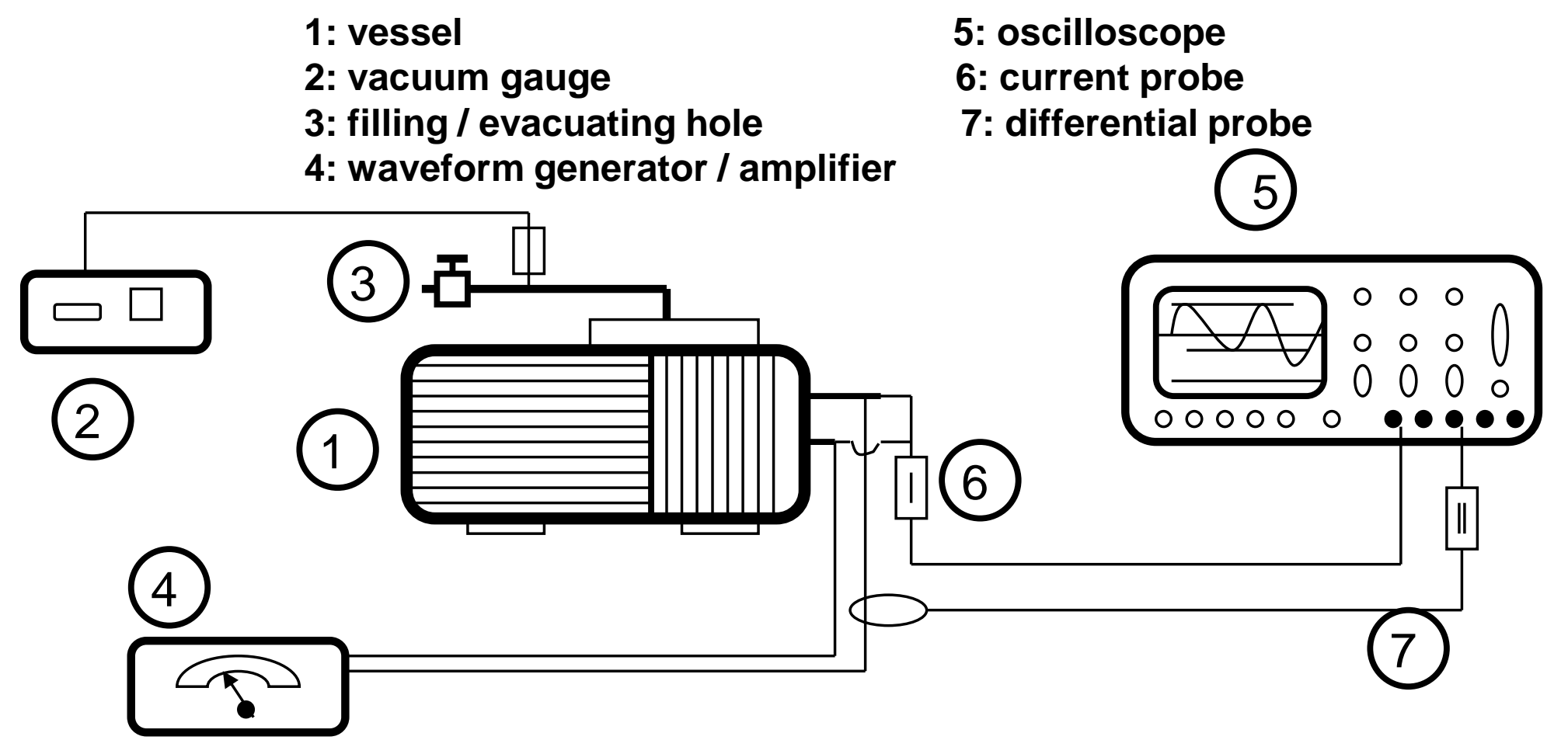

5: oscilloscope

6: current probe (2)

: filling/ evacuating hole 


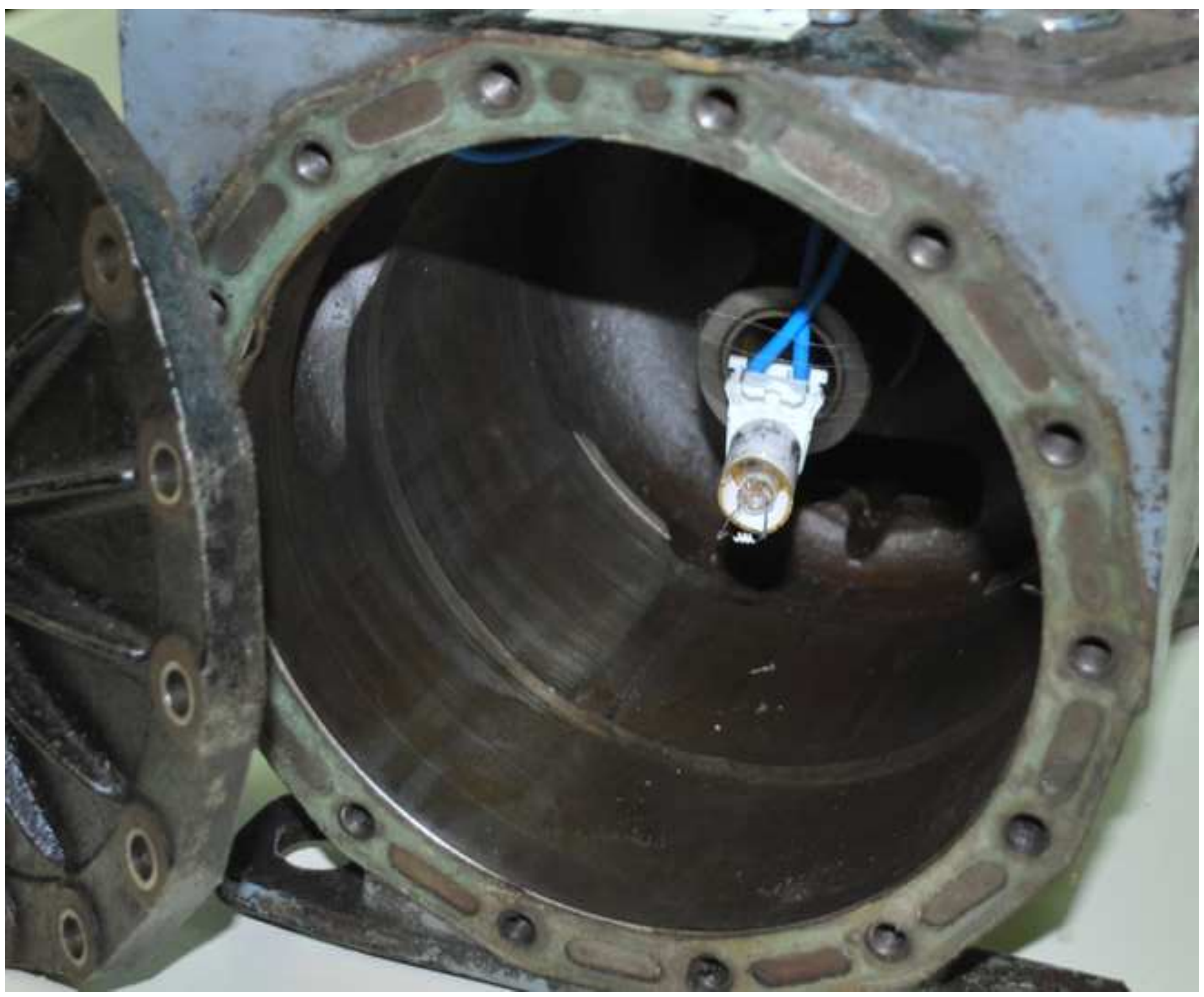

o download high resolution image 

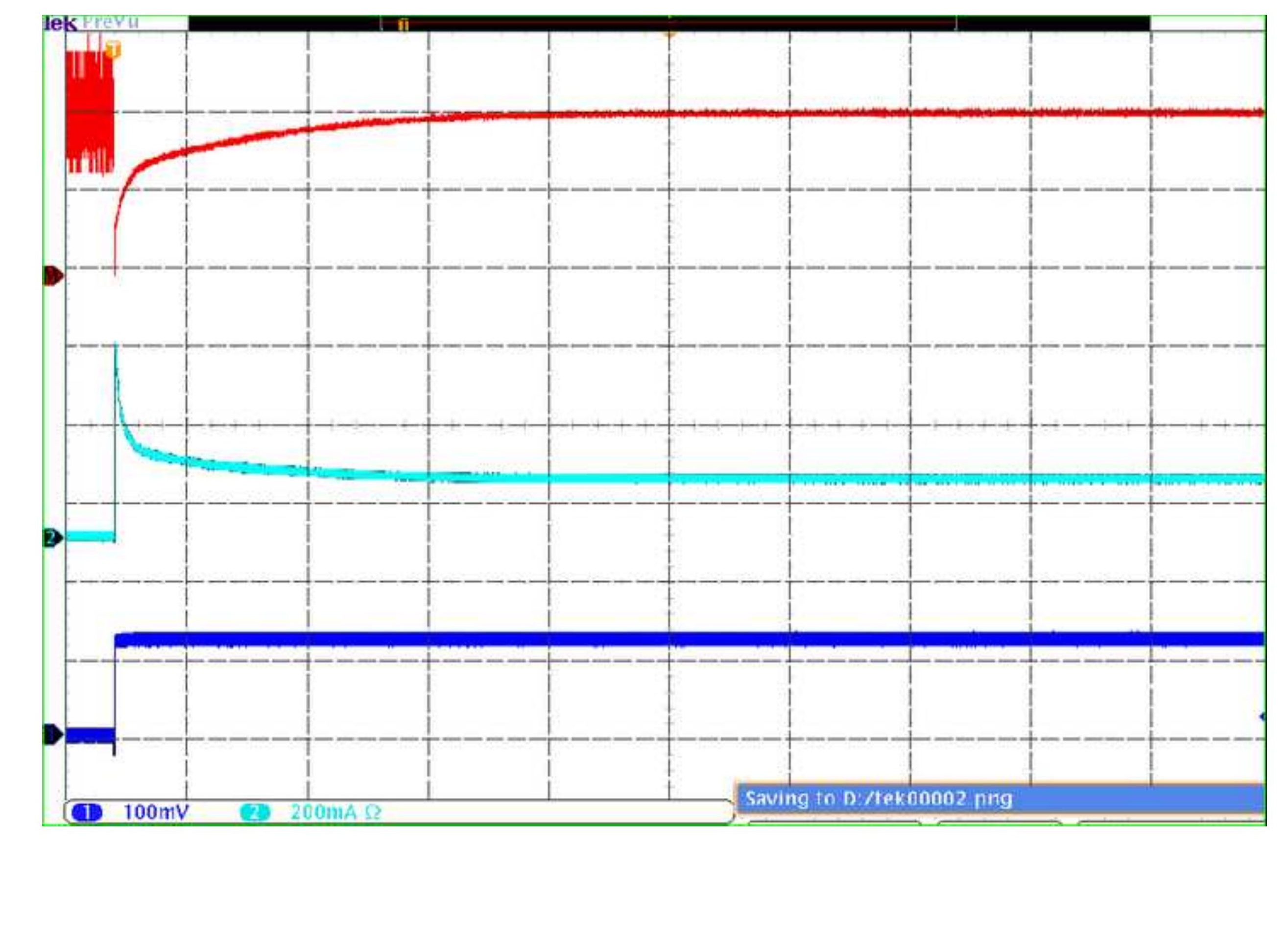


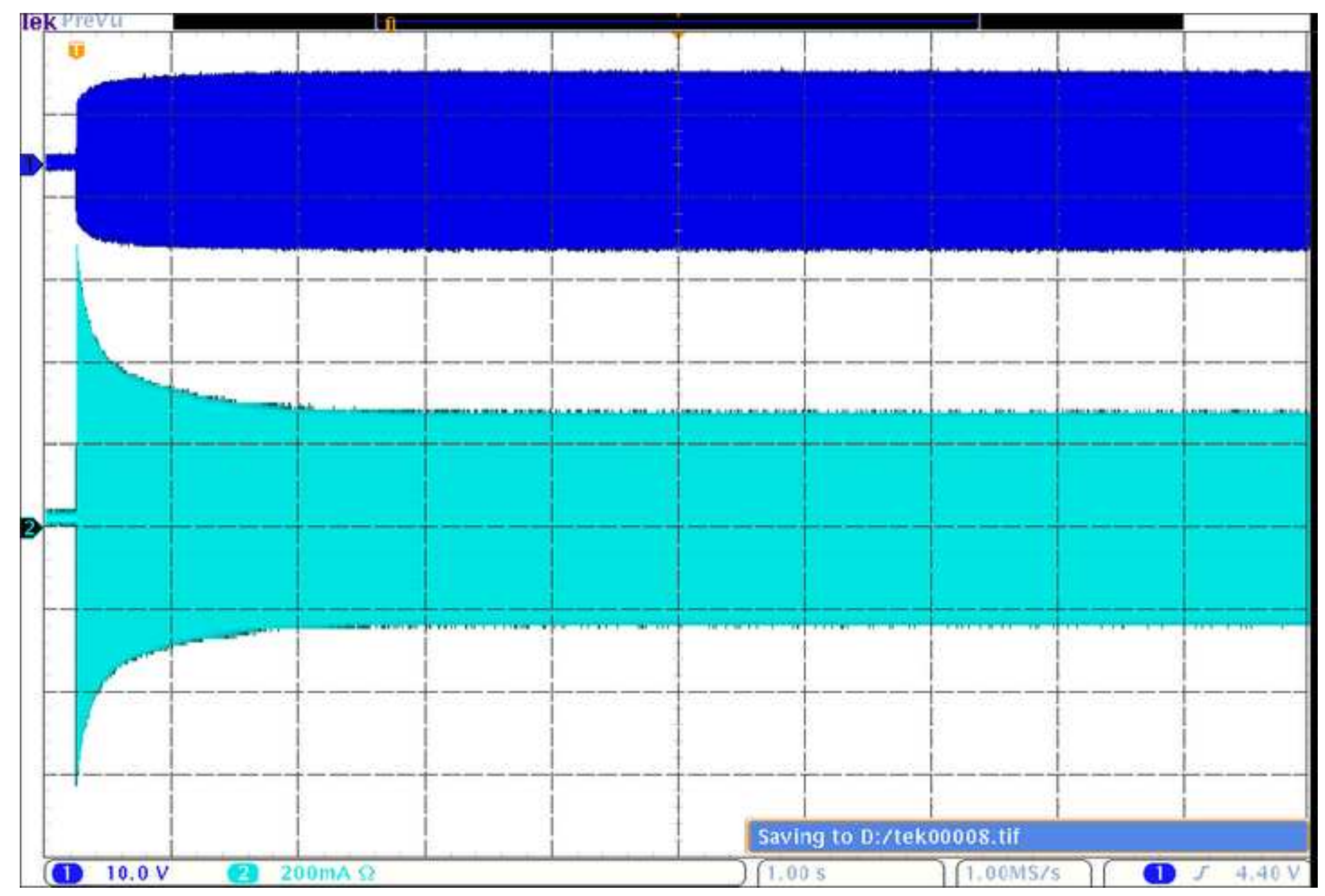




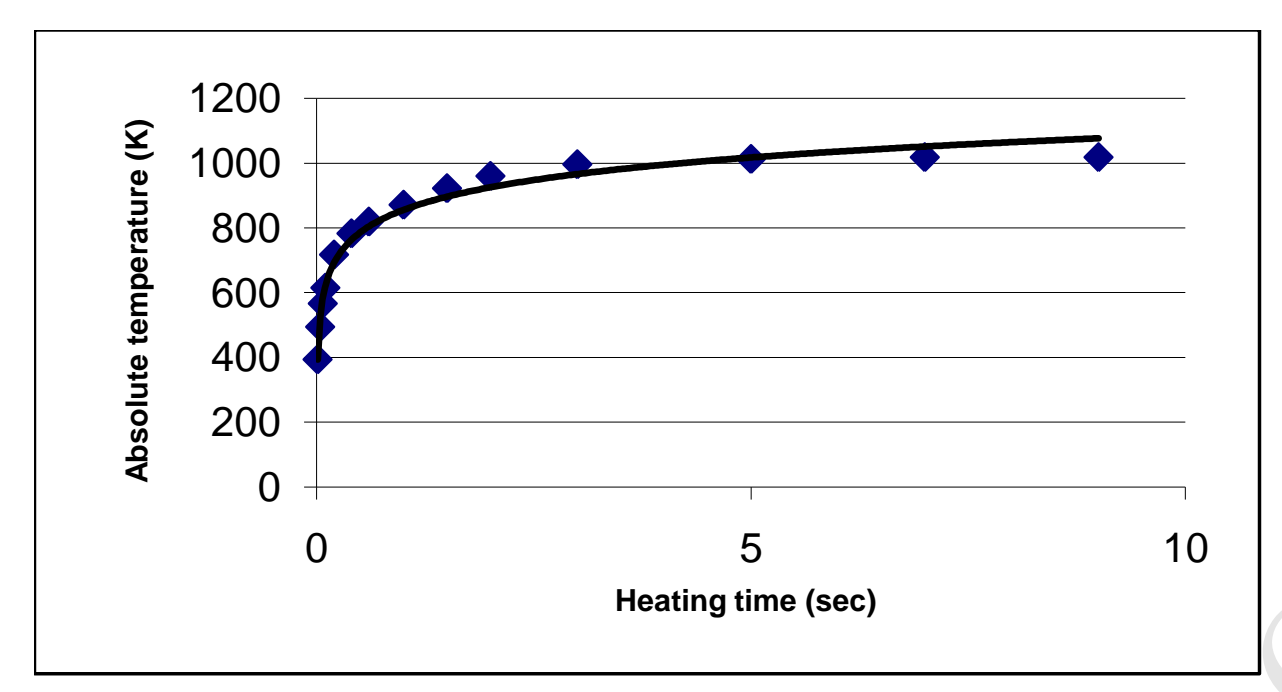

Heating time (sec) 
Figure(s)

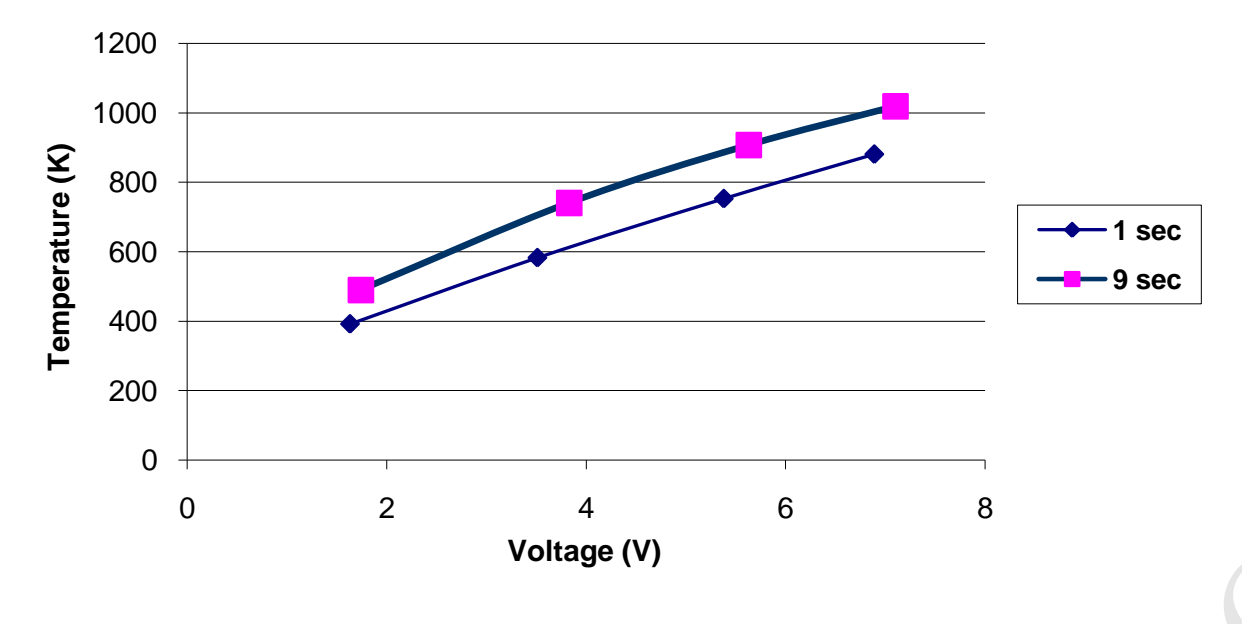

Vltage (V)

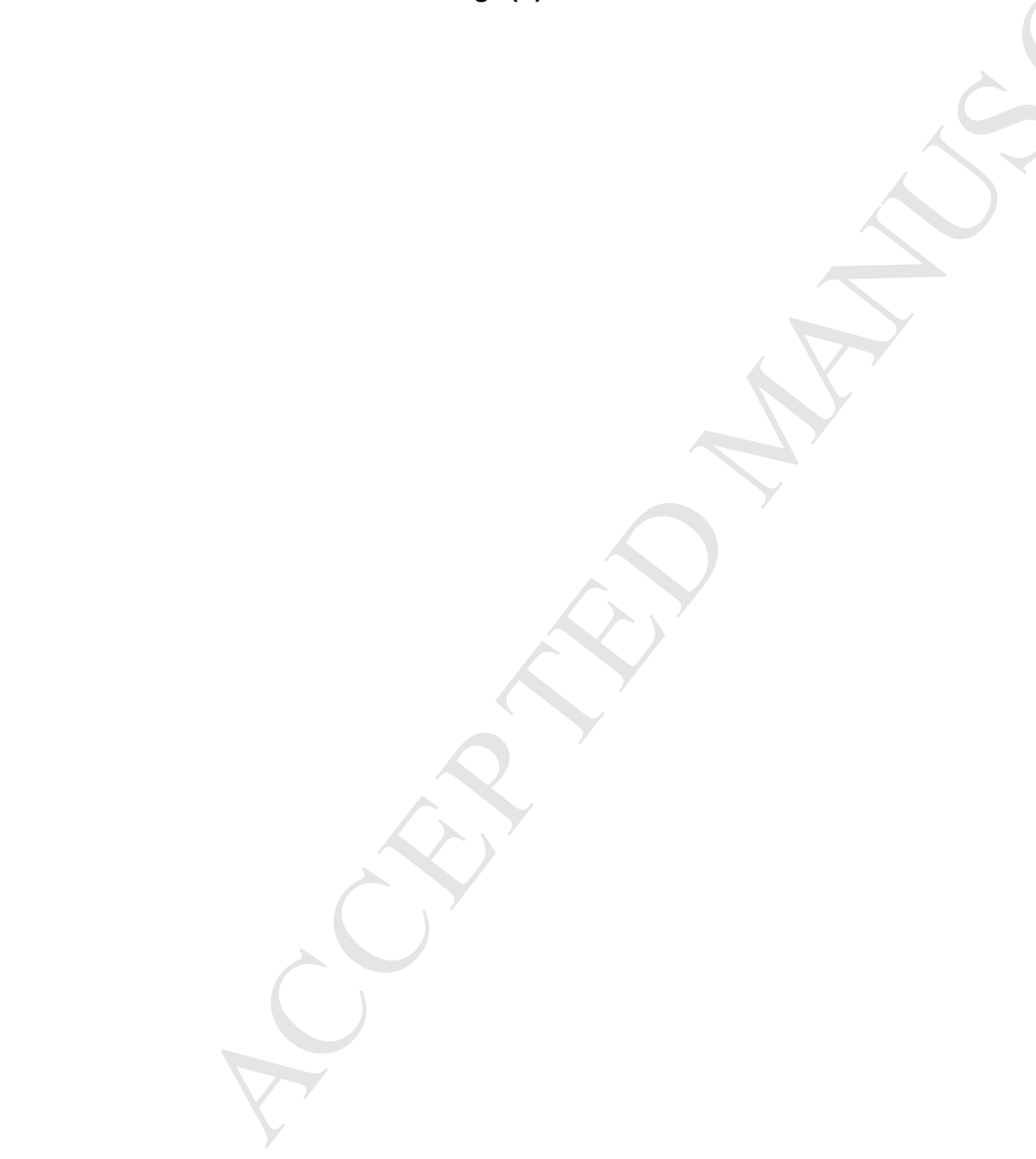

8

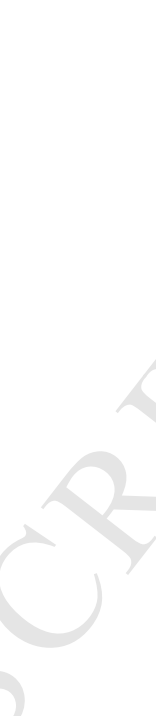

\section{ACCEPIED MANUSCRIPI}

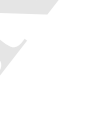




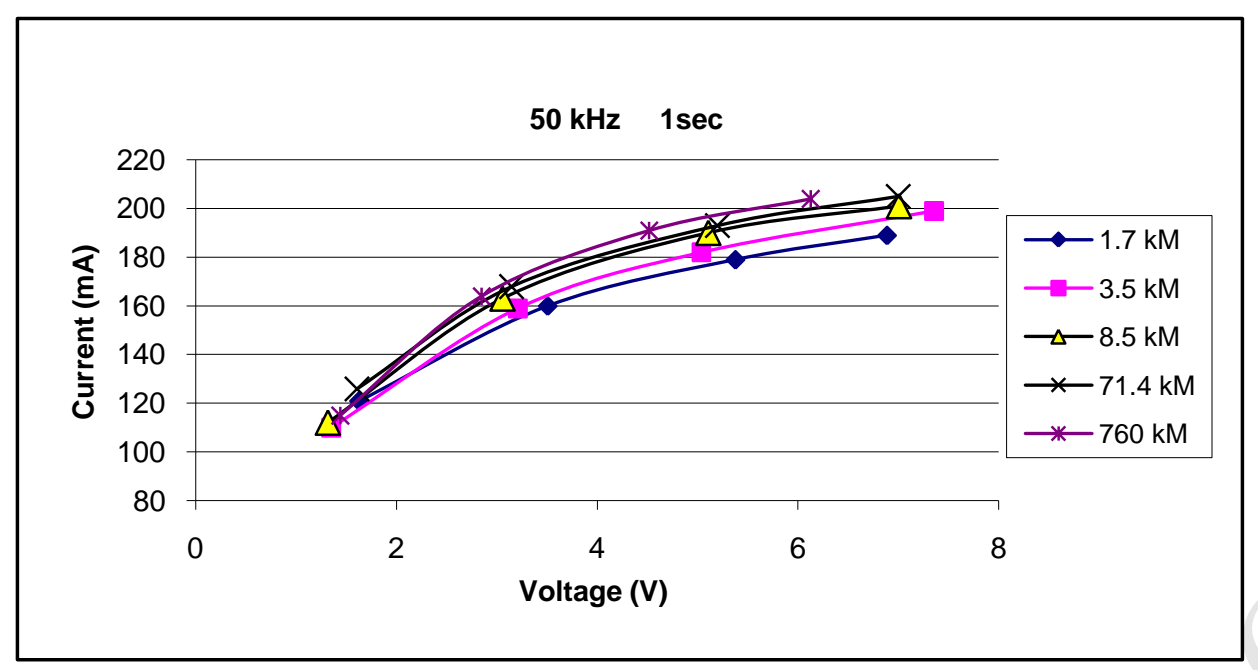




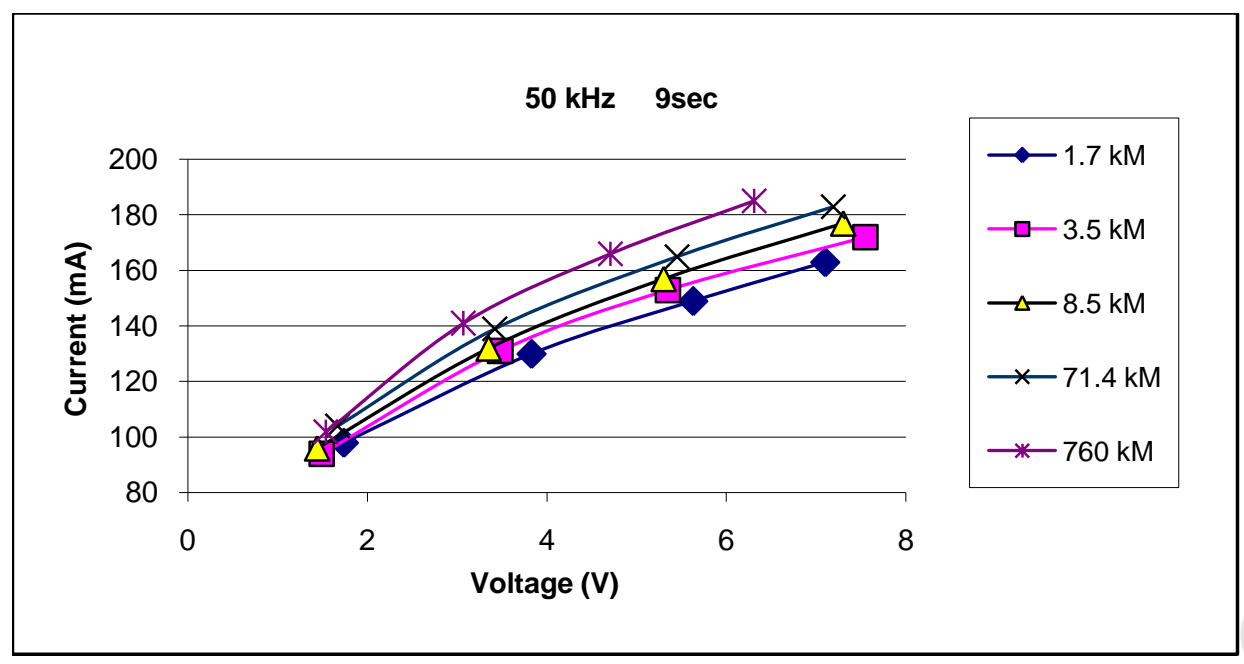




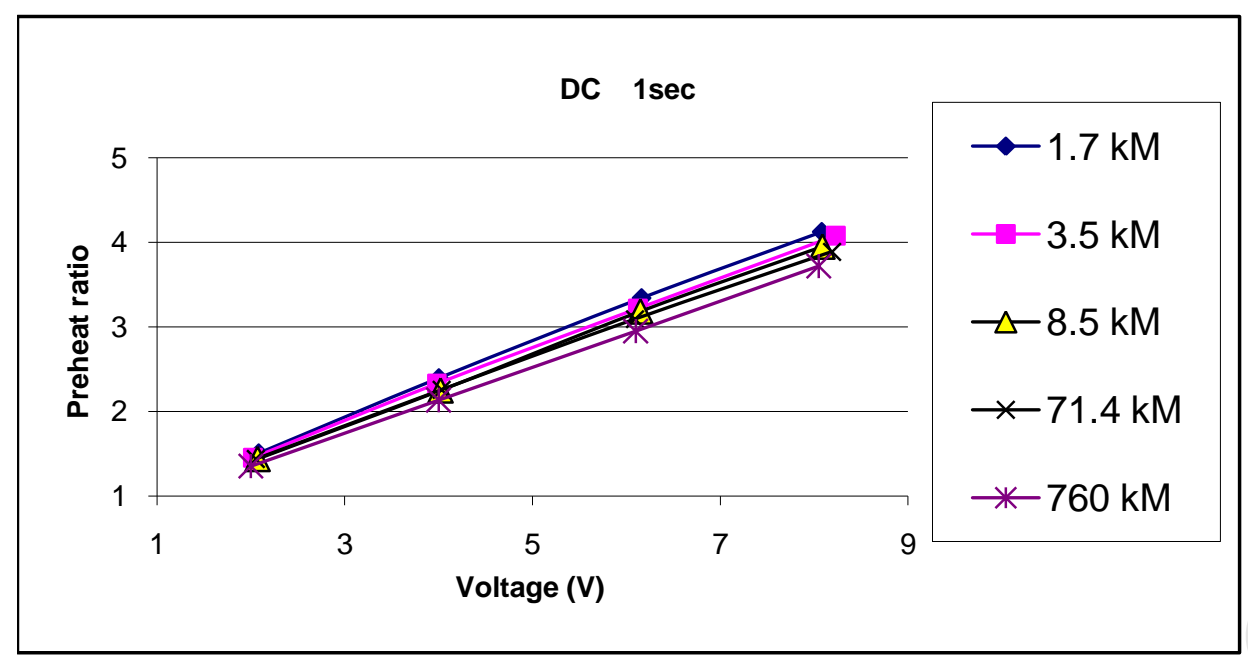




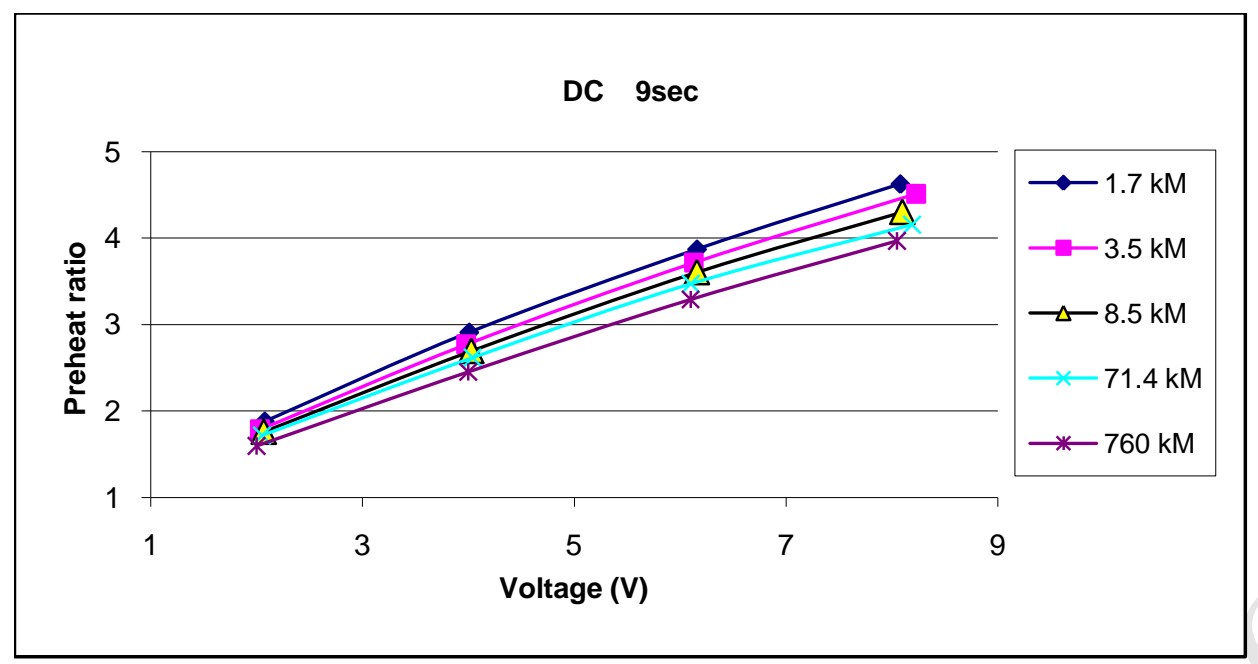




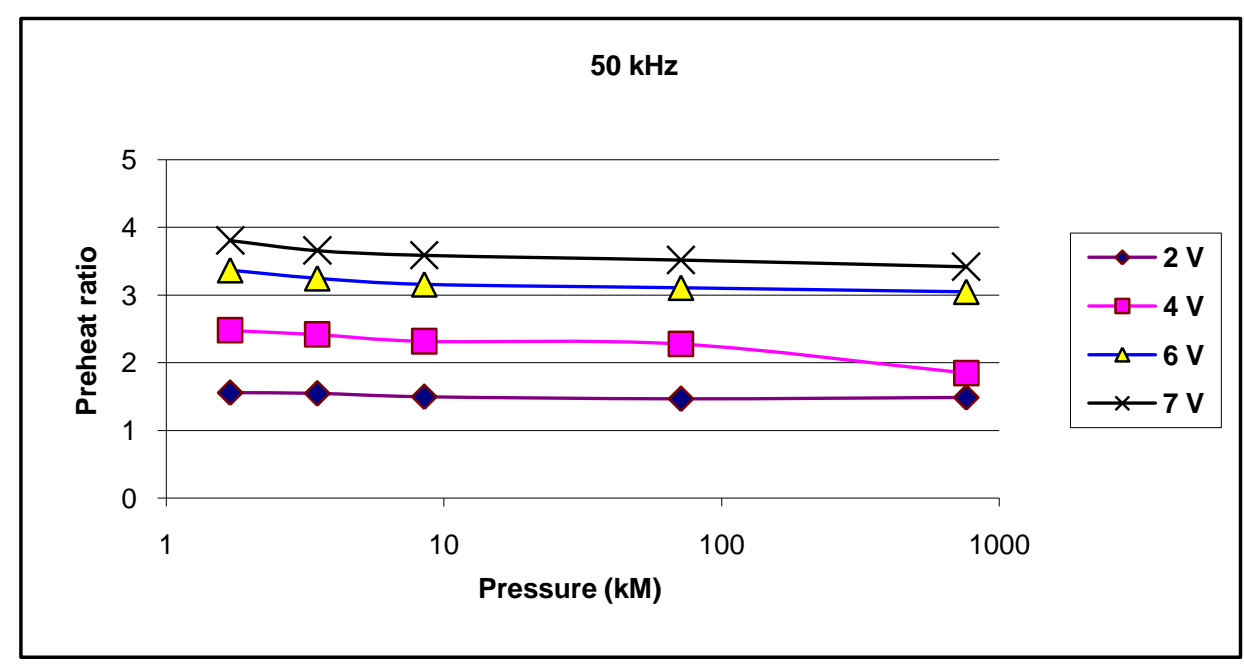




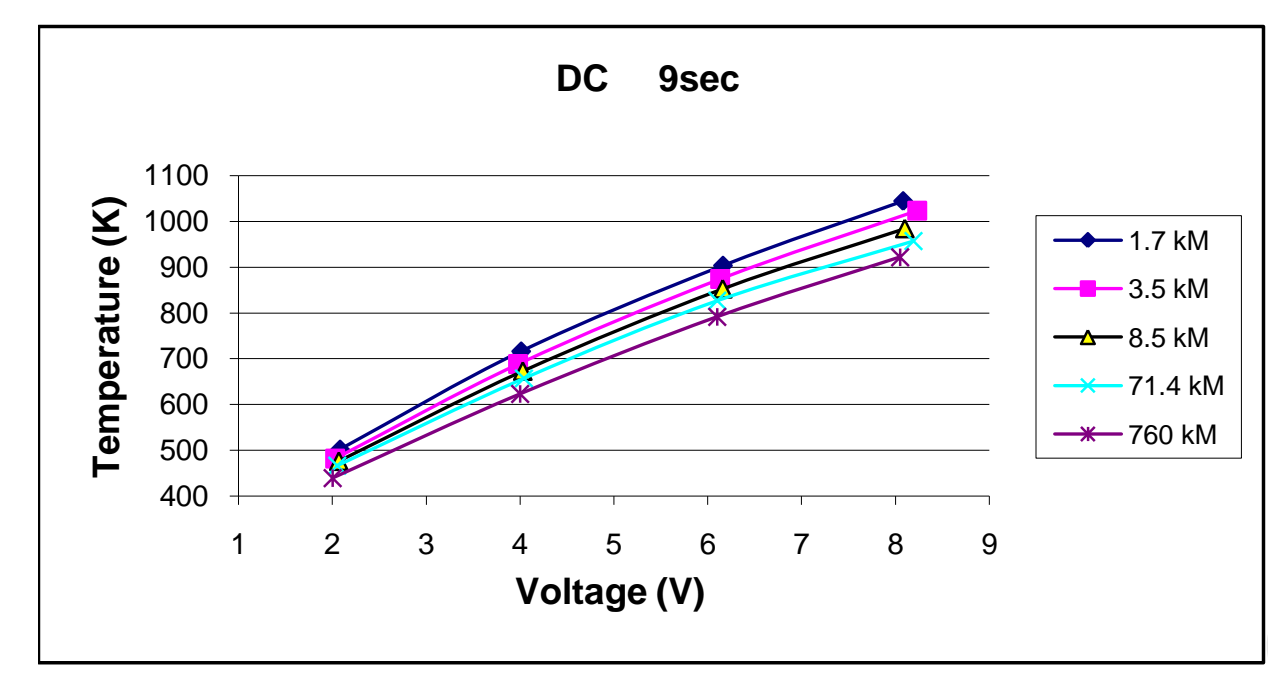




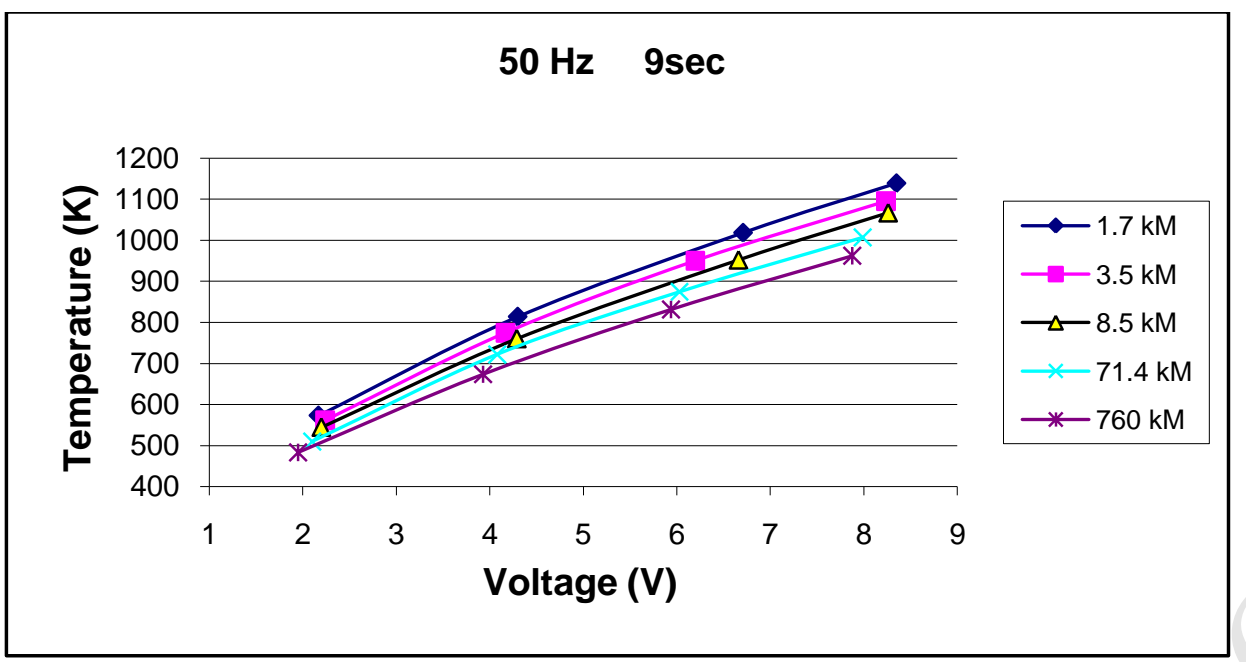

, 


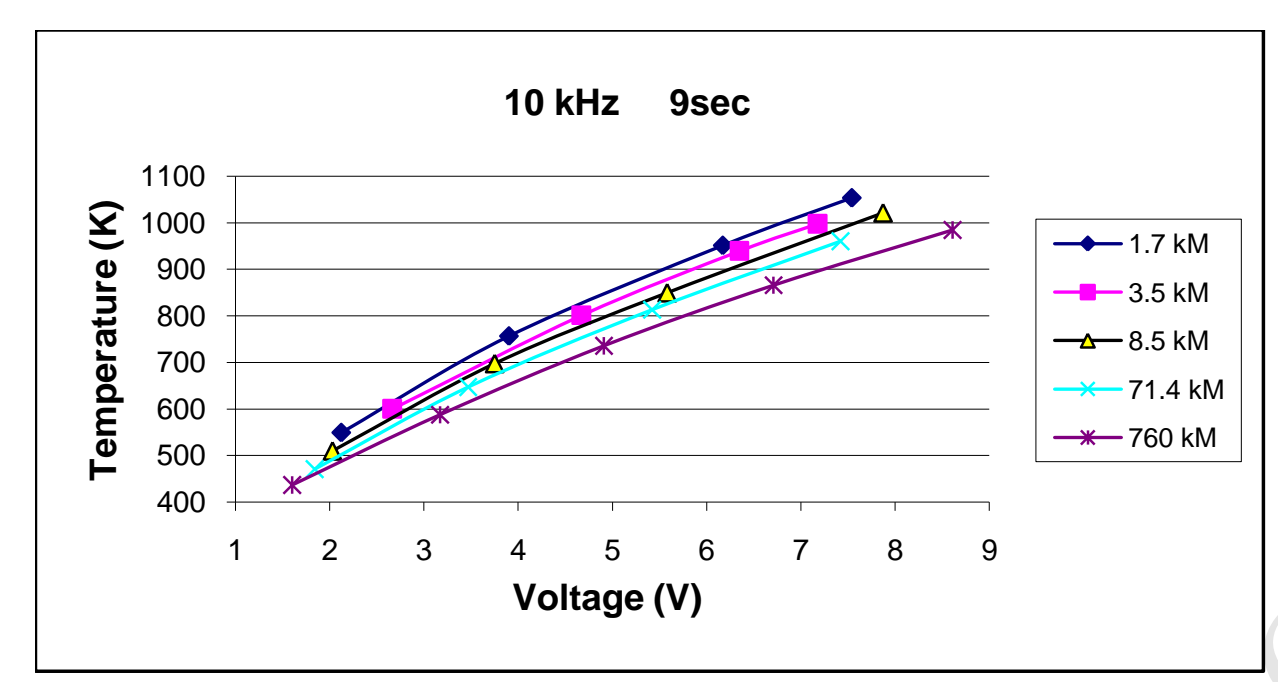




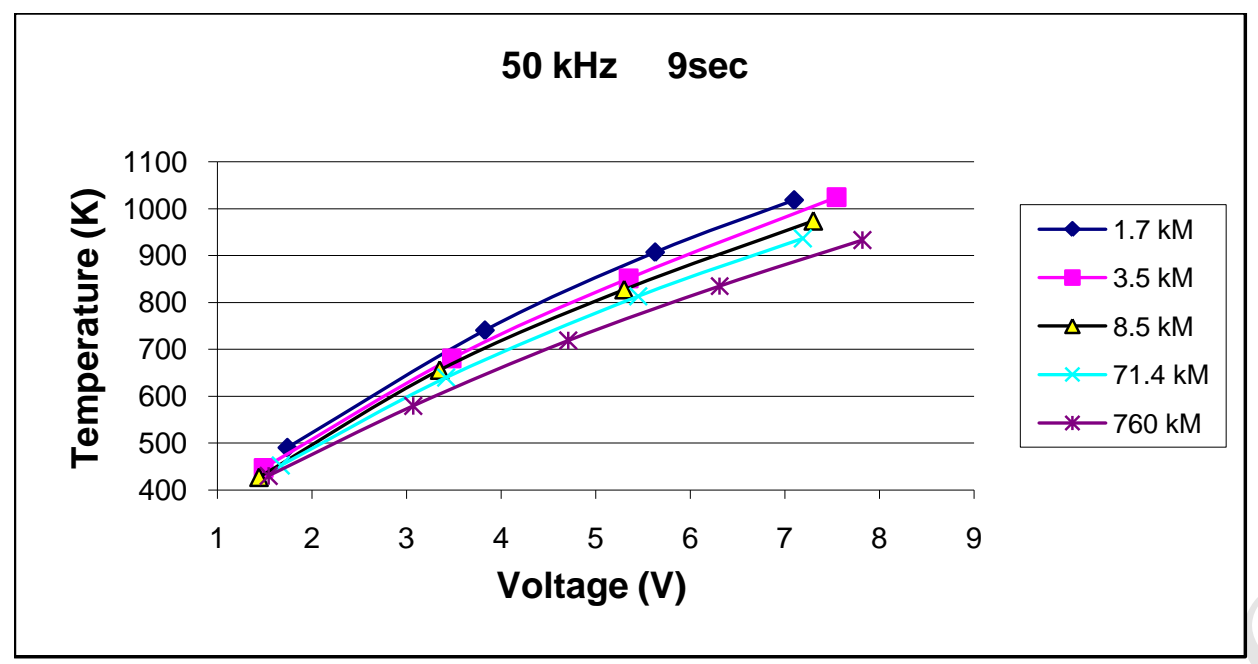




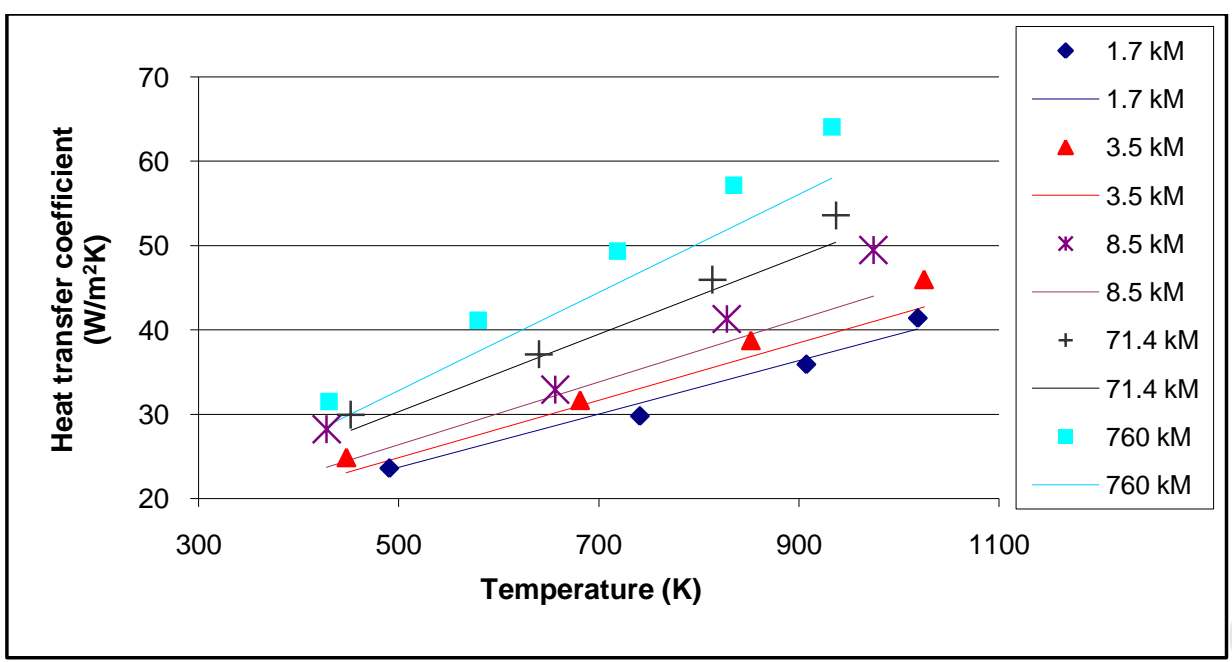




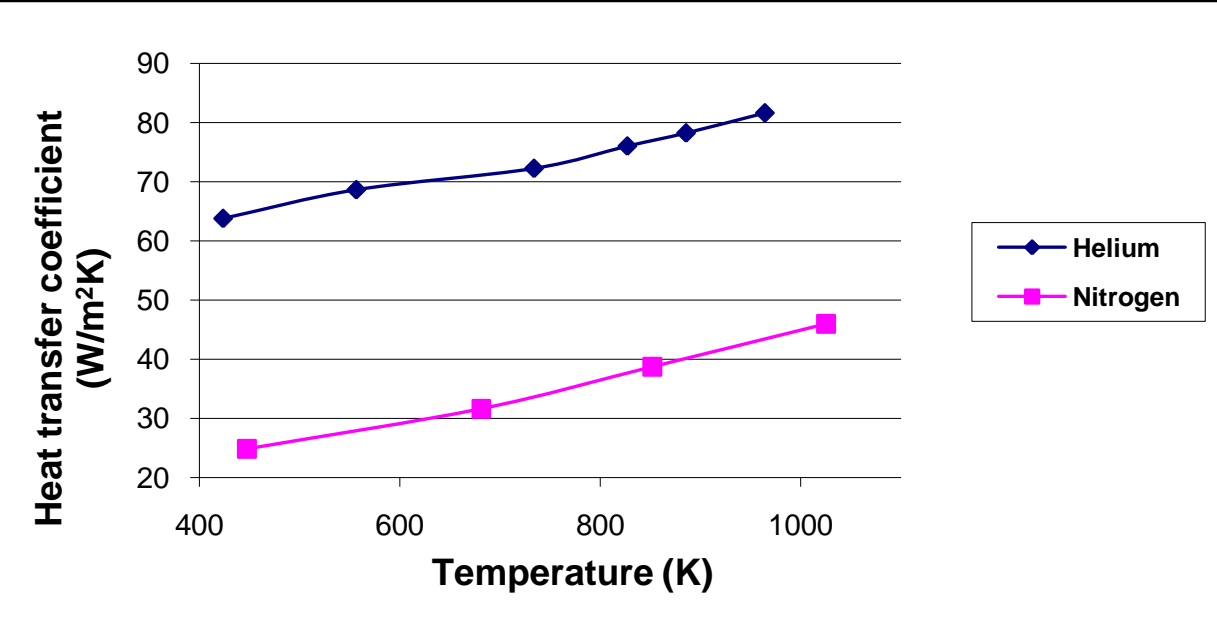

